JOURNALISTS' ROLE CONCEPTIONS

IN COVERING SEXUAL VIOLENCE

POST-WEINSTEIN

A Thesis
presented to
the Faculty of the Graduate School
at the University of Missouri-Columbia
In Partial Fulfillment
of the Requirements for the Degree
Master of Arts
by
BECK JAECKELS
Dr. Amanda Hinnant, Thesis Supervisor
DECEMBER 2020


The undersigned, appointed by the dean of the Graduate School, have examined the thesis entitled

\section{JOURNALISTS' ROLE CONCEPTIONS \\ IN COVERING SEXUAL VIOLENCE \\ POST-WEINSTEIN}

presented by Beck Jaeckels,

a candidate for the degree of Master of Arts,

and hereby certify that, in their opinion, it is worthy of acceptance.

Professor Amanda Hinnant

Professor Katherine Reed

Professor Cristina Mislán

Professor Rachel Bailey 


\section{ACKNOWLEDGEMENTS}

First and foremost, I would like to thank my committee - Dr. Amanda Hinnant, Professor Katherine Reed, Dr. Cristina Mislán, and Dr. Rachel Bailey - for their expertise, assistance, guidance, and patience throughout the process of writing this thesis. This project could not have been completed without all of you.

I would like to thank Dr. Berkley Hudson for fostering my passion for research at the collegiate level, from my first days as your Discovery Fellow to your willingness to undertake the Cherng Summer Scholars program as my mentor. I would also like to extend my gratitude to Dr. J.D. Bowers and the University of Missouri Honors College, for always encouraging my curiosity and desire to learn.

Thanks to Mark Horvit, Dr. Monique Luisi, Dr. Tim Vos, Dr. Ryan Thomas, Pete Bland, Jeanne Abbott, and Laura Johnston for guiding me through my graduate studies and helping me to grow as a journalist as well as a researcher.

Approaching the topic of sexual violence coverage as a survivor is a difficult task, so I am grateful for the supportive community of teachers, mentors, family, and friends who have helped me complete this project. 


\section{TABLE OF CONTENTS}

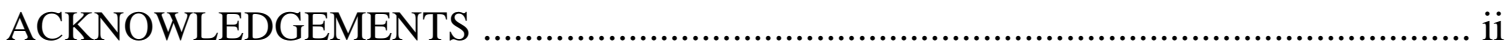

LIST OF FIGURES ...................................................................................... iv

1. INTRODUCTION ................................................................................ 1

Goals of the study .................................................................... 6



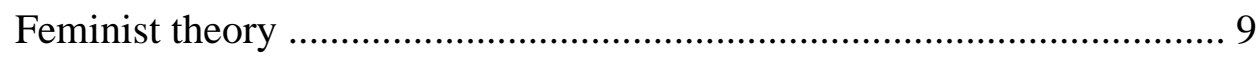

Rape culture and reporting ........................................................ 12

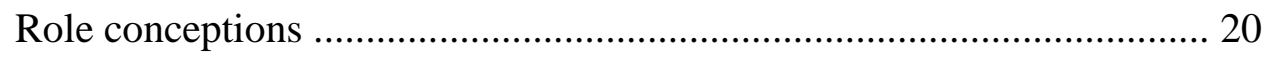

Research questions .................................................................... 22

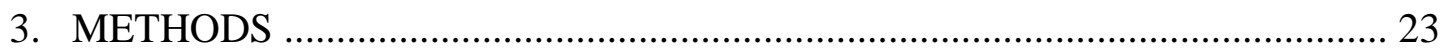

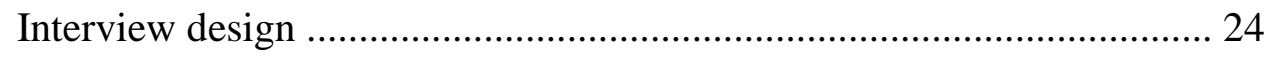

Trauma in participants ............................................................ 28

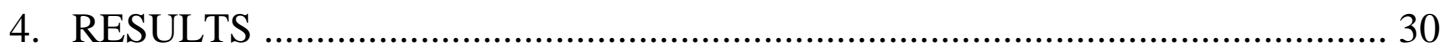

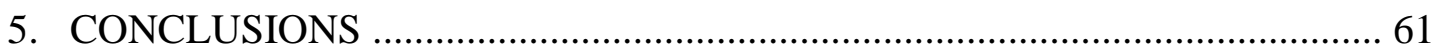

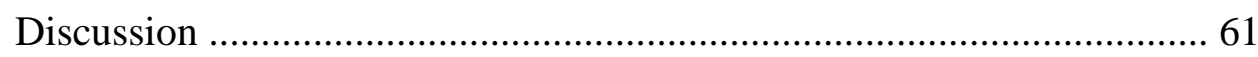

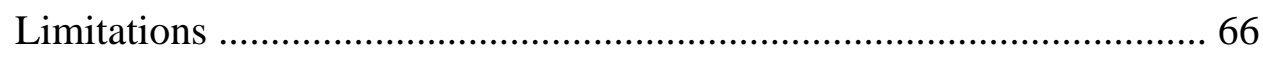

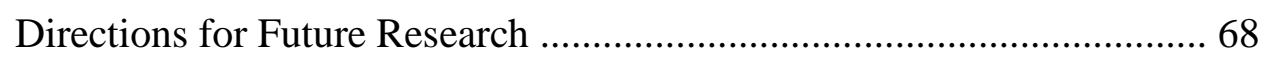



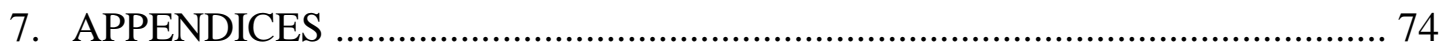




\section{LIST OF FIGURES}

$\begin{array}{lll}\text { Figure } & \text { Page }\end{array}$

1. Ms. Magazine November cover, 1977 ................................................................. 3

2. Screenshots of replies to tweets from @SheRatesDogs, @ colleenriley42, and @MichaelaOkla detailing accusations of sexual harassment and predation of underage girls against comedian Chris D'Elia ................................ 18

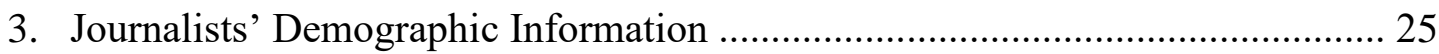

4. Four Roles in Reporting on Sexual Violence Post-Weinstein ............................... 55 


\title{
JOURNALISTS' ROLE CONCEPTIONS \\ IN COVERING SEXUAL VIOLENCE \\ POST-WEINSTEIN
}

\author{
Beck Jaeckels \\ Dr. Amanda Hinnant, Thesis Supervisor
}

\begin{abstract}
Since the publication of The New York Times article on Harvey Weinstein, journalists across the United States have had to adapt to a new reporting climate as it has evolved under the influence of the \#MeToo movement. This thesis explores the reporting, editing, and decision-making processes used by journalists when discussing incidents of sexual violence. The purpose of this study is to understand how journalists chose to discuss individuals issuing accusations, perpetrators, and misconduct and investigations and whether the unique conditions of the \#MeToo movement and post-Weinstein period affected this thought and decision-making process. Twelve journalists took part in indepth interviews discussing their experiences reporting on sexual violence. Based on their answers, journalistic roles were conceived and discussed specific to the coverage of this traumatic event.
\end{abstract}




\section{Chapter 1: Introduction}

On October 5, 2017, The New York Times published a story online by Jodi Kantor and Megan Twohey entitled "Harvey Weinstein paid off sexual harassment accusers for decades." The next morning, it ran as a front page story in the paper's print edition. What followed was a global conversation about the prevalence and dynamics of sexual violence, leading to the creation of foundations like Time's Up, a nonprofit aiming to create a society free of gender-based discrimination in the workplace and beyond. Since that initial story published, significant checkpoints have defined that conversation. Among the recognizable names brought to trial - either in the court of public opinion or through the criminal justice system - were then-Supreme Court nominee Brett Kavanaugh, financier Jeffrey Epstein, anchor Matt Lauer, musician R.Kelly, former-vice president Joe Biden, director Bryan Singer, CBS chief Les Moonves, astrophysicist Neil deGrasse Tyson, comedian Bill Cosby, actor Morgan Freeman, comic creator Stan Lee, sports doctor Larry Nassar, and actor James Franco. Some cases have all but been forgotten in public discourse; others have resulted in lasting convictions. Exactly 873 days after Kantor and Twohey's article published, on February 24, 2020, the first verdicts in a case against Weinstein were announced: guilty of criminal sexual assault in the first degree and rape in the third degree, not guilty on two counts of predatory sexual assault (The New York Times, 2020). Weinstein's conviction, however, is not the culmination or apex of a movement intended to hold sexual predators accountable for their actions on a broader scale; it is the revitalization of one decades in the making. 
Journalists have a role to play in continuing that mission, seeking out stories that hold those in power accountable and presenting themselves as a resource to the survivors who want to share their stories. In the time since the initial exposure of Weinstein's crimes, journalists across the United States have had to adapt to a new reporting climate as it has evolved under the influence of the \#MeToo movement. This "post-Weinstein" period is "the cultural fall-out from the Weinstein revelations, ... one fraught with both great promise and peril" (Cobb and Horeck, 2018, p. 489). Reporting of stories of sexual assault, abuse, violence, and harassment now fall under the umbrella of this movement. The aim of this research is to gain a greater understanding of how journalists view their duties as communicators of sexual violence in the wake of that movement, as well as how they subconsciously navigate feminist ideology in their coverage of sexual violence, focusing specifically on stories reported following the initial The New York Times article. This study attempts to understand how journalists chose to discuss survivors, perpetrators, and misconduct and investigations and whether the unique conditions of the \#MeToo movement and post-Weinstein period affected this process.

Sexual harassment did not yet have a name in the public discourse when $M s$. Magazine highlighted the subject in its November 1977 issue (Figure 1). The magazine featured a cover that used the traditionally comforting image of a child's doll to make its point - a distinctly male hand thrust into the top of the doll's dress (Bennett, 2017). Within a notably heteronormative context, rape accusations and the act of rape itself have historically been treated as crimes against men - either as an injury to a man's reputation or an offense against a woman's father or husband. Women were relegated to roles merely as objects of sexual arousal that caused men to respond to what were perceived as 
their natural biological urges. But these are not ideas only from centuries past. Amnesty International UK found in a 2005 survey that, among those interviewed, more than a quarter said that they thought a woman was partially or totally responsible for being raped if she was wearing sexy or revealing clothing, and more than one in five held the same view if a woman had had many sexual partners.

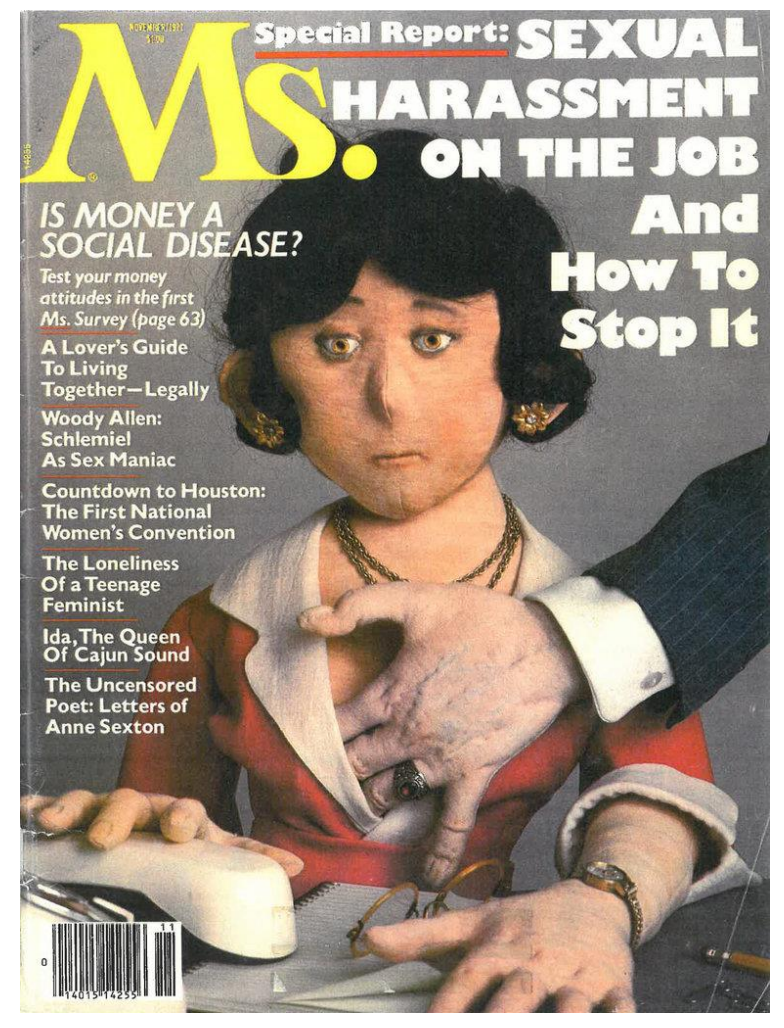

Figure 1: Ms. Magazine cover, November 1977

Traditionally, the broader public learns about sexual violence through the news media, and even then, only in cases that are deemed relevant to the public interest by law enforcement - for instance, if a perpetrator poses a sustained threat or is a household name. As the digital sphere grows, social media is playing an increasingly significant role in alerting audiences to incidents of assault and harassment at all levels and in all social 
circles - it is not only celebrities' experiences with sexual violence that catch the eye of the public. This interaction with social media works to counteract the tendency of mass media to provide representations of assault and harassment that are provocative but not representative (Barnett, 2014). Still, news media are a significant authority on what can and cannot be said about sexual violence. Representation in all forms of media helps determine how both the accuser and the accused are discussed in the public sphere. Covering sexual trauma is no easy task: Incorrect terminology has the potential to cross legal barriers, aggressive lines of questioning can retraumatize survivors, and trial in the court of public opinion often does not coincide with the verdict given in a courtroom. For every 1,000 rapes that occur, 994 perpetrators walk free (RAINN, 2015). On average, only 57 of those individuals are ever even arrested. How journalists decide to approach stories about sexual violence carries weight. For survivors, choosing to tell their story may be the only form of justice that they get. In September 2019, Chanel Miller decided to make public that she was the woman Brock Turner sexually assaulted in 2015. Turner was convicted of three charges of felony sexual assault but served only three months in jail. For Miller, telling her story was cathartic: "When you keep something so contained, it restricts you from getting the help and support you need" (Brockes, 2019).

Following the initial publication of The New York Times article, the \#MeToo movement swelled in both online and news communities. The movement originated with the work of activist Tarana Burke in 2006, but it gained new traction as survivors began to come forward and share their stories following the public accusation of Weinstein (Millner, 2018). The purpose of the \#MeToo movement is to counter sexual predation and violence (Stephens, 2018). Under the influence of \#MeToo, journalists are prompted 
to reconsider their responsibilities in covering sexual violence, particularly regarding how their choice of words, images, metaphors, and common phrases influence how audiences perceive stories (Easteal, 2014). Armstrong and Mahone (2017) found that willingness to participate in action against sexual violence is higher in environments where it is treated as a prominent community concern by news organizations. After being presented with thorough reporting on sexual violence, readers retain "increased knowledge of sexual violence, decreased acceptance of rape myths, increased prosocial bystander attitudes, increased bystander efficiency, and increased self-reported bystander behaviors" (Armstrong and Mahone, 2017, p. 97). Armstrong and Mahone (2017) propose that, if rape culture myths desensitize individuals to the occurrence of sexual violence, then responsible social media exposure will instead make consumers more likely to mobilize against a culture that enables sexual violence. It seems possible, then, that traumainformed and comprehensive reporting on sexual violence creates a more knowledgeable reader base that is more likely to become active in combatting a culture of assault and abuse.

Existing scholarly literature analyzes the broader social conversation surrounding sexual violence but does not address how news coverage in all three acts of trauma reporting - the incident, recovery and resilience, and the search for meaning - contributes to and informs this public discourse (Ochberg, 1999). News stories about sexual violence are not limited to covering the event or legal action in close temporal proximity to their occurrence. Survivors may come forward long after experiencing sexual violence, or the nature of the story a journalist is covering may not deal with a single specific incident. 
No matter where a survivor is at in their journey or an individual incident has progressed, the stories that journalists tell and how they choose to tell them carry weight.

\section{Goals of the Study}

Little research follows the \#MeToo movement and considers how this may have altered or reinforced the norms surrounding the conversation on sexual violence. That amount diminishes further when looking specifically at the response and duties of journalism. The work that does address this issue is most often not scholarly, so this study has a role to play in stimulating that conversation. The results of this study will, hopefully, have consequences for future news coverage of sexual violence. Despite the onset of the wider \#MeToo movement in October 2017 and the subsequent restructuring of survivor and perpetrator narratives, two years of discussion does not negate decades of rape culture enforcement and patriarchal gender assumptions. Still, the researcher hopes the results will show an increased conscientiousness towards treatment of survivors as interview subjects and story characters.

This study is not a one-and-done solution, but another much-needed step forward on a path towards conscientious and educated trauma reporting. In looking beyond textual and content analysis, this study seeks to understand the very culture in which stories on sexual assault are pitched, researched, reported, and shared. As the "first draft of history," journalism has a responsibility to its readers and subjects to tell a truth, no matter what the complexities of that truth might be. In the case of sexual assault, that means increased education on how trauma might affect a victim's ability to recall the event. That means avoiding victim-blaming frames not only through one's own writing, but also through the quotes attributed to experts and witnesses. That means making a 
conscious effort to avoid frames that fetishize and romanticize aspects of sexual assault because of the inherent sensationalism and colorful language associated with these storytelling methods. There is a gap fit for this research to fill. This thesis is a piece of a grander puzzle - a necessary foundation for further analysis into how journalists cover instances of sexual violence, which in turn serves the larger purpose of improving how journalists interact with and represent victims and survivors of traumatic events. In basic terms, this study seeks to understand how journalists describe their experiences covering sexual violence after \#MeToo and their journalistic role conceptions. 


\section{Chapter 2: Literature Review}

Coverage of sexual violence influences how the public perceives both survivors and perpetrators, as well as how society defines what constitutes a violation in the court of public opinion. For the purposes of this study, definitions of key terms are sourced from previous research and U.S. legal designations. The United States Department of Justice defines sexual assault to include "any type of sexual contact or behavior that occurs without the explicit consent of the recipient" - this includes being forced or coerced into sexual behavior that was undesired or nonconsensual (Champlin, 2017). Explicit consent means that an individual is clearly presented with an option to agree or disagree with the sexual contact or behavior. An individual who is under the influence of alcohol or drugs, unconscious, or otherwise incapacitated cannot provide explicit consent. This standard is looser than Senate Bill 967, or the "Yes Means Yes" Law, which was enacted in California in 2014 (Chappell, 2014). California SB 967 defines affirmative consent as the standard for cases of sexual assault: "Lack of protest or resistance does not mean consent, nor does silence mean consent. Affirmative consent must be ongoing throughout a sexual activity and can be revoked at any time."

Sexual violence includes unwanted sexual advances - including verbal, coercive, physical, and sexual events (Fountain, 2008). O'Hara (2012) defines rape myths as "prejudicial, stereotypes or false beliefs, prejudices or stereotypes about rape, rapists, and rape victims" (p. 247). The survivor is the individual who says that they have experienced sexual violence. The word "victim" can be problematic for some who have experienced sexual violence because it can imply weakness or a loss of agency; these individuals 
prefer the word "survivor" in order to stress strength in overcoming the abuse, though terminology used by journalists should be determined on a case-by-case basis in alignment with the specific preferences of the individual experiencing violence (Blanding, 2017, p. 38). This study uses "victim" in the literature review when quoting directly from research but will use "survivor" in all other instances. The perpetrator is the individual accused of or convicted of committing the act of sexual violence.

\section{Feminist theory}

This paper approaches the topic of sexual violence from a feminist perspective. At the foundation of feminist theory is the idea that society is based upon gendered constructions that "organize identity, social participations, and the standards for judging self and others" (Boyle, 2012, p. 1). Feminist scholars understand sexual and family violence as being primarily perpetrated by men against women and being about domination rather than sexual desire (Easteal, 2014). This doctrine leads critics of feminist theory to accuse theorists of criminalizing ordinary heterosexual encounters when calling attention to instances of sexual violence; feminist definitions of sexual violence are blamed for ruining sex for heterosexual couples by identifying traditionally heterosexual dynamics as power imbalances (Harrington, 2018). This accusation employs the "feminist killjoy" trope - the idea of the feminist ruining the fun by calling attention to what is inherently problematic about a relationship's dynamics (Harrington, 2018). Harrington (2018) identifies this critique as indicative of the call-and-response relationship of feminism and misogyny - one inherently invokes the other. Given that sexual violence is a crime rooted in misogyny and control, regardless of the gender 
identities of the individuals involved, feminist critique and theory is an integral part of its discussion. While the core definition of feminism is founded in discrimination based on gender, it is important to understand what exactly is being meant when using the term "gender" - and what is left out when that term is oversimplified. This means considering the influence of sex, gender, gender identity, gender performance, and sexual orientation on the relationship dynamic between the individuals involved in a case of sexual violence (Dorer and Hipfl, 2013). A comprehensive feminist perspective considers the intersections of human identity wherever they may lie - race, gender, sexuality, class, age, ability, and others - but the traditionally gendered nature of sexual violence makes these particular intersections essential to consider.

Since the 1970s, feminists have been working to challenge traditional media discourse surrounding rape and sexual violence (Harrington, 2018). News media has, however, been the slowest genre of media to change in response to feminist criticism (Harrington, 2018). News coverage represents a significant source of information regarding sexual violence - it is often the first point of contact for the public. Feminist analysis shows that this coverage is inherently flawed, with reporting taking on a "male perspective that perpetuates stereotypes and myths about women while ridiculing and trivializing their needs and concerns" (Boyle, 2012, p. 1). Reporters often unconsciously employ the same rape myths that have defined the public conversation on sexual violence. Rape myths are a feminist construct and represent a commonplace discourse on rape which perpetuates stereotypes of survivors and perpetrators (Harrington, 2018). When the effects of this patriarchal norm are minimized or ignored, media takes on a postfeminist lens in which feminist thought and analysis are considered arbitrary, with 
the justification that society has progressed past the need for this movement (Darmon, 2014). Essentially, when news media stops being critical of its own coverage of sexual violence, it reinforces the belief that popular conceptions of sexual violence are unproblematic and are not subject to the influence of patriarchal norms. Rather than breaking down the nuances behind the prevalence and severity of sexual violence in modern society, these stories hyper-focus on individual incidents - a result of the postfeminist belief that feminist-defined causes for rape culture (and rape culture itself) are a thing of the past. This most often splits contemporary mainstream media coverage between tones of ignorance and dismissiveness of the realities of sexual violence. Feminist analysis of sexual violence discourse positions individualization as part of a pervasive ideology that supports or excuses assault (Burt, 1980). Individual experiences are emphasized, but without the context of larger societal issues that enable and excuse sexual violence. McDonald and Charlesworth (2012) found that 88 percent of texts framed sexual harassment as an individual event, ignoring broader societal trends.

This individualization of the issue extends into news coverage. Easteal (2014) cites a feminist theory that posits that news media treat violence against women as isolated incidents, rather than as a wider problem within the dynamics of social male dominance. It is important to reclassify Easteal's idea within terms of traditionally feminine and masculine qualities and how those inform feminist understandings of power dynamics in sexual violence. Society and feminist thought traditionally assume survivors to be female and perpetrators to be male, which is why cases of sexual violence that do not fit a traditional female-survivor-male-perpetrator model are not covered in the same way. The overall goal of feminist scholarship is advancement towards social justice, 
equality, and inclusion (Dorer and Hipfl, 2013). In some cases, this means qualifying statements by feminist scholars or updating them for contemporary understandings of gender identity, performance, and dynamics.

\section{Rape culture and reporting}

Maxwell (2014) defines rape culture as "a culture in which sexual violence is the norm and victims are blamed for their own assaults" (p. 1). American media coverage of sexual violence supports the infrastructure of an extensive rape culture through its framing and choice of visible stories. Fountain (2008) argues that journalists "construct accurate and ... sound articles but still miss the point of the event, thereby reinforcing stereotypes and public misunderstanding" (p. 34). This sort of coverage lends itself to the perpetuation of rape myths, including the suggestion that all women are aroused by forced sexual domination or that individuals like to be talked into having sex (Armstrong and Mahone, 2017). Other rape myths dominate sexual violence discourse. StubbsRichardson (2018) identifies seven rape myths: they asked for it, they wanted it, they didn't mean to, they lied about it, it wasn't really rape, rape is a trivial event, and rape is a deviant event (p. 92). In the interest of considering cases that do not adhere to gendered rape myths, these have been altered to use gender-neutral language. Burt (1980) attributes

acceptance of rape myths to deeply rooted beliefs such as role stereotyping, distrust of the opposite sex, and acceptance of interpersonal violence. Journalists rely on rape myths when an instance of sexual violence does not fit the mold of "real rape" (Franiuk, 2008, p. 2). "Real rape" is modeled as an animalistic man brutally taking advantage of an unsuspecting woman. The word "rape" conjures the colloquially familiar image of a woman passed out in a fraternity house; cases that do not conform to that expectation are 
either dismissed or distorted when viewed through a lens compliant with rape myths that fit a preconceived understanding of the world. Contemporary methods for reporting sexual violence to law enforcement suggest that individuals place themselves at risk by not adhering to social norms (Fountain, 2008). This might mean that stories focused on male or masculine-presenting survivors of sexual violence use the individual's supposed weakness or perceived lack of masculinity as justification for the assault. Media frames often focus on the survivors rather than the perpetrators of sexual violence, but not in a way that invokes empathy or furthers the survivor's search for justice or meaning. Because of the prevalence of law enforcement as the media's primary source for stories of sexual violence, details are often scarce and identities are withheld from those sharing these stories. Journalists are left to write about impersonal stand-ins for survivors and perpetrators rather than named individuals, and the lack of specific knowledge often results in the dependence on rape myths. Rather than focusing on survivors as a human subject with a story, the resulting frames position survivors as the variable that could have somehow prevented the assault, highlighting rape avoidance strategies and selfdefense tips, especially for women ( $\mathrm{Li}, 2017)$.

Crime victims face social stigma due to the perception that they do or say something that contributes to their being harmed (Fountain, 2008). Sexual violence survivors in particular are often perceived to be responsible for the trauma that they experience, and 75 percent of survivors are likely to blame themselves in the same way that rape myths deem they should be blamed (Li, 2017). Victim-blaming in news coverage is often the result of focusing too strongly on the individuals in the case. Stubbs-Richardson (2018) draws relationships between victim-blaming ideology and the 
just-world hypothesis, which assumes that individuals receive morally fair consequences and outcomes based on their behaviors. The just-world hypothesis would assume that someone would not be subject to sexual violence if they had followed behavioral expectations; therefore, they must have done something wrong to invite that violence. Victim-blaming isn't always done directly by journalists. Quotes that journalists choose to include that showcase the opinions of survivors' neighbors or acquaintances may do this in their stead (Voinea, 2015). Franiuk (2008) notes that American culture prides itself on a perceived valuation of respect of personal integrity and punishment of those who violate that integrity. Sexual violence is a serious violation of this integrity, so moral consistency would demand that those who violate this cultural norm be severely punished. This isn't the case. But admitting that failure would mean admitting a failure of that core American value. What is sought instead, then, is control and predictability. Franiuk (2008) argues that people have a powerful incentive to maintain rape myths in order to assign predictability and control to these events: "If this woman who is not promiscuous, who was not dressed provocatively, who clearly did say 'no' and was with her boyfriend was sexually assaulted, what's to prevent me from getting sexually assaulted too?" (p. 3).

The media plays a vital role in the political and social life of a civilization, informing public conversation and shaping individuals' schema (Boyle, 2012). As a result, journalists must confront a difficult conundrum: how to talk about something you can't prove happened (Blanding, 2017). Columbia University's Dart Center for Journalism and Trauma Executive Director Bruce Shapiro notes that covering trauma forces journalists to confront their own "prejudices and preconceptions, fears, past 
experiences, and ethical conflicts" (Blanding, 2017, p. 36). Journalists, therefore, have an innate responsibility to produce more nuanced and informative journalism on sexual violence. $\mathrm{Li}$ (2017) noted that newspaper reading was significantly correlated with increased victim-blaming and perpetuation of "victim myths." However, the same studies found a positive relationship between the amount of media coverage and the public's perception of an issue's importance. It's a line that journalists must walk carefully then: produce the necessary amount of coverage but ensure that you are able to devote the resources necessary to make any coverage productive and constructive. Journalists generally feel that they approach sexual violence reporting ethically, with mistakes resulting from a lack of knowledge and not an active effort to silence or discredit survivors; they also tend to believe others would be unlikely to change their coverage approach simply because of new guidelines (Hohman, 2015). Armstrong and Mahone (2017) assert that the willingness to mobilize against sexual violence would be greater for those who have experienced it, those who are highly aware of sexual violence, and those who have greater knowledge of sexual violence through media reports - lending credence to the importance of comprehensive coverage.

Siefkes-Andrew and Alexopoulos (2018) found that a majority of stories about sexual violence contained language of support, but nearly 40 percent included verbs that implied doubt or illustrated explicit doubt of survivor's statements. As journalists attempt to avoid accusations of libel or slander, they often rely on language that carries consensual connotations. Journalists are likely to slip into language implying consensual sex - "had sex with" or "fondled" - rather than words like "raped" or "molested" (Blanding, 2017, p. 38). It's a line that journalists must carefully toe. Katie Feifer, leader 
of CounterQuo, a national coalition of groups working with media to change the way sexual violence is covered, advises that "if you would use words with your intimate partner, do not use those words to describe sexual violence" (Blanding, 2017, p. 38). O'Hara (2012) found that perpetrators are transformed into an "other" and distanced as "beasts." (p. 251). Survivors, in comparison, are often presented as virgins attacked by monsters or as promiscuous individuals who invite rape and are to blame (O’Hara, 2012).

When personal information becomes available, the news frame may reflect the impression that the survivor said or did something to deserve being the target of sexual violence, resulting in readers attacking their character (Fountain, 2008). Boyle (2012) argues that identifying a survivor, by name or other characteristics, does nothing to help facilitate understanding of the crime of rape because it has nothing to do with why they were assaulted. Boyle (2012) notes that, in the United States, survivors of sexual violence rely on a "conspiracy of silence" to protect their privacy that is based on understanding rape as a personal, traumatic, and stigmatized crime (p. 3). If journalists break this rule, there will likely be no legal repercussions. The United States Supreme Court has always protected the media's right to release the name of a sexual assault survivor under the protection of the First Amendment (Boyle, 2012). It is, however, worth noting that some studies did find that identification of survivors by name did increase empathy regardless of the survivor's gender, and that inclusion of personal information can reduce victimblaming (Anastasio and Costa, 2004).

Carlyle, Slater, and Chakroff (2008) argue that the power of a frame can be as great as that of language itself. Journalists must decide primarily between thematic framing, which contextualizes issues and emphasizes social responsibility, and episodic 
framing, which emphasizes individual circumstances and responsibility (Easteal, 2014). The fragmented nature of news perpetuates traditional views of sexual violence by discussing elements out of context, meaning that journalists often must rely on episodic framing that produces an environment ripe for the introduction of rape myths (Franiuk, 2008). The withholding of details by law enforcement, Title IX offices, and other gatekeepers of information about sexual violence largely shape this fragmented representation of sexual violence. Journalists fall back on readymade clichés involving sex and gender instead of giving a nuanced account of the facts (Boyle, 2012). Anastasio and Costa (2004) argue that how the media represent groups affects the perceptions of those groups and influences the subsequent treatment of these groups. Readers respond to the portrayals of both the survivor and the perpetrator. If news media routinely portray survivors negatively, it can result in readers misplacing blame and fault in the situation (Fountain, 2008).

Victim-blaming is a common story frame used in stories about sexual violence, which promotes rape myths and reinforces preexisting misconceptions ( $\mathrm{Li}, 2017)$. Franiuk (2008) found that "they are lying" and "they wanted it" were the most commonly perpetuated myths (p. 2). Examples of this can be seen in the recent case of comedian Chris D'Elia. As survivors shared their stories on Twitter, commenters accused them of doctoring screenshots and lying for attention. 

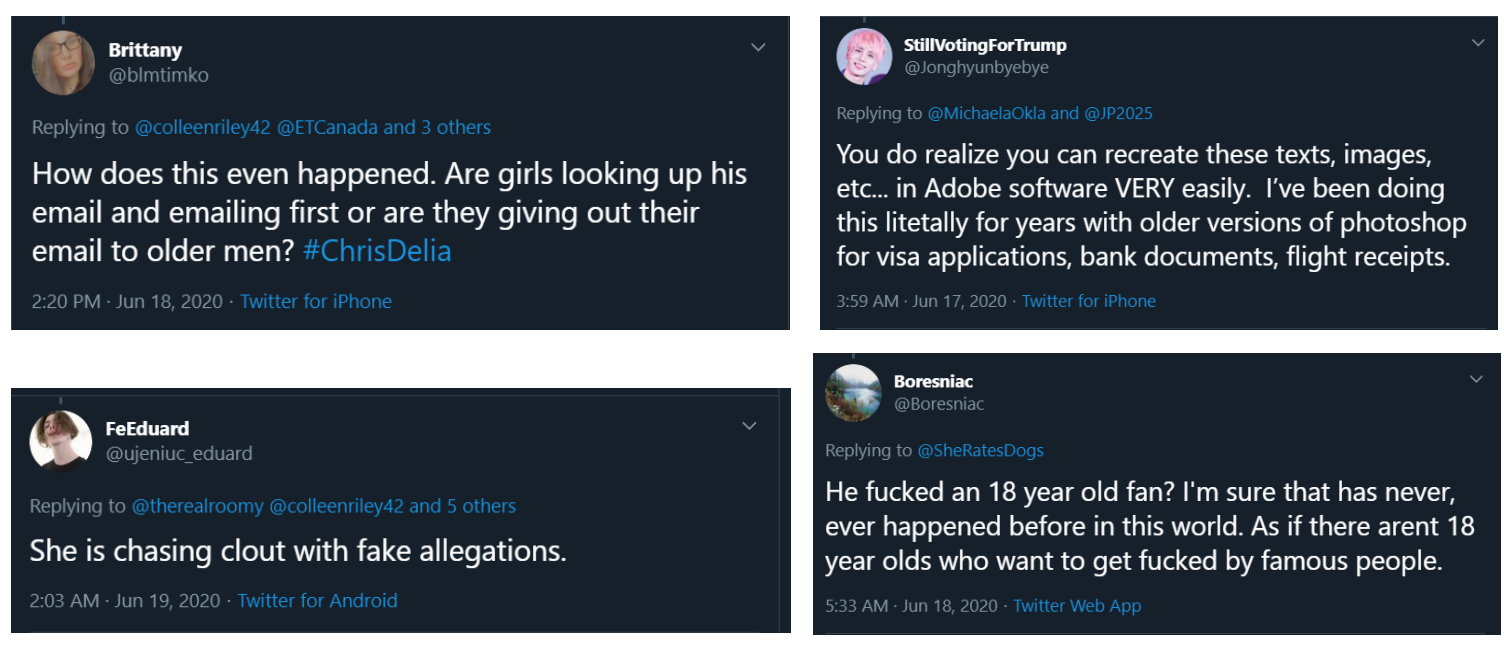

Figure 2: Screenshots of replies to tweets from @SheRatesDogs, @colleenriley42, and @MichaelaOkla detailing accusations of sexual harassment and predation of underage girls against comedian Chris D'Elia.

Stubbs-Richardson (2018) identified three themes or frames related to rape culture: the virgin-whore binary and the just world, sharing information regarding sexual assault cases as sub-news, and rape myth debunking to support survivors. The last frame is seemingly the least common in traditional media, based on the results of previously discussed studies.

Stories about sexual violence tend to ignore the second and third acts of trauma reporting, which focus on stories of resilience and the search for meaning. The 2015 Berkley Media study found that more than half of stories about sexual violence focus on criminal justice milestones such as arrest and trial. Only 6 percent mentioned treatment for survivors, and only 8 percent discussed prevention strategies - in part because a majority of stories are crime reports rather than longform pieces focused on survivors' experiences. This report recommends once more that journalists go beyond focusing on specific incidents to consider the "landscape" of sexual violence, view sources outside of the criminal justice system, and look at how survivors recover from acts of violence a 
year or more after they occur (Blanding, 2017). Advocates recommend a comprehensive list of reforms:

"Avoidance of vocabulary suggesting the woman deserved or enjoyed the assault, obtaining balance so that if the victim's sex life is mentioned so might the suspects, including a context which might allow people to protect themselves, showing consideration of the families and victims and developing training for reporters and editors so that they learn to recognize the myths and stereotypes in their own reporting." (Boyle, 2012, p. 6)

Hohman (2015) asserts additional rules: Do include statistics to convey accurately the frequency of the crime, do not describe what the survivor was wearing, avoid using "alleged," attribute facts to the people who said them, ask the survivor if they would like to be identified, and give options for the amount of personal information disclosed. These rules do assume that the journalist has direct access to the survivor in the case, which may not be the case if law enforcement chooses to withhold that information.

Past reporting on sexual violence also raises issues concerning verification of stories. Kroll (2015) cites the Rolling Stone case, in which compromises were made during the reporting process that resulted in false allegations being released in a major publication. What could have been avoided by a better balance of survivor support and enforcement of journalistic standards became a failure of verification that cast doubt on other reporting of sexual violence. Responsible reporting on sexual violence is not about believing. It is about listening - to the survivor, to the perpetrator, to the concerns of editors and fact-checkers. McDonald and Charlesworth (2012) implore journalists to consider who is given a voice, who is silenced, which themes are emphasized, and which themes are marginalized or excluded. Hewitt (2017) proposes a single answer to the question of dealing with false charges as a small fraction of cases of harassment and 
assault: "cautiously, with due process for the accused, always in court but also in the press, and via reference to a single standard, not one that bends to partisan pull" (p. 1). By looking to past recommendations on covering sexual assault and traumatic events, we can begin determining what work has yet to be done.

\section{Role conceptions}

Journalists' conceptions of their roles - professionally, personally, and within broader social structures - can influence how they write news, which in the area of sexual violence reporting influences how the public treats survivors. Vos (2005) defines journalistic role conception as a journalist's own formulation of how they ought to function in society and clarifies that journalistic responsibility should function as an indicator of professionalism, rather than the other way around (p. 3). Clarke-Vivier and Stearns (2019) assert that important roles within the context of the \#MeToo movement include public pedagogy - "educative work in extrainstitutional spaces" - and bearing witness (p. 61). Zelizer (1993) proposes a model of journalism in which the press functions as an interpretive community for the public, providing "shared discourse and collective interpretations of key public events" (pg. 219). In this model, communities arise through "the informal associations that build up around shared interpretations" (Zelizer, 1993, pg. 223). Journalists' jobs would be to supply the interpretations that allow for the formation of new informal associations that do not rely on rape myths. Where, then, do these roles fit within journalist's conceptions of their own roles, particularly in covering the \#MeToo movement? What cannot be addressed by this question, though, is whether these journalists are effective in their roles. Civic, watchdog, 
and service-oriented journalists experience gaps between their conceptualized roles and the actual performance of those roles (Mellado and van Dalen, 2014, p. 872). As such, it is important to address journalists' own conceptions of their role effectiveness in conversations with journalists about role conceptions.

Four roles will serve as a starting point for discussion. These roles are based in part on those put forth by Christians et al. (2009) in discussing normative theories of the media - monitorial, facilitative, radical, and collaborative - but have been adapted to better account for the specifics of sexual violence coverage. For the purposes of this study, journalistic roles will be classified as follows: monitorial, radical, interpretive, and humanistic. In this study, the monitorial role asks that journalists act as a watchdog on all forms of power and authority, whether that be a government body or other dominant group. In coverage of sexual violence, this could mean monitoring justice systems or simply perpetrators. The radical role, as defined for this study, requires the elevation of views outside of the mainstream for the purpose of progressive social change. Journalists fulfilling the radical role would advocate for conscious undermining of rape culture and significant changes to justice and accountability systems. For the purposes of this study, the interpretive role asks that the media facilitate conversation while interpreting discourse for the public. It is largely adapted from Christians et al.'s (2009) facilitative role and would encourage conversation around sexual violence. The humanistic role's goal is to enrich lives and unpack meanings of cultural artifacts, which in the case of sexual violence would mean focusing largely on the individuals affected by the incidents. These stories would primarily focus on the second and third acts of trauma reporting, dealing with resilience and the search for meaning. 


\section{Research Questions}

In the proposal and planning stages of this thesis, the researcher anticipated that journalists would report significant changes in newsroom dynamics and the reporting process following the popularization of the \#MeToo movement. This did not materialize, and the research questions for this study were revised. While the influence of the \#MeToo movement was not nonexistentabsent, it was secondary to existing understandings of trauma and sexual violence in responses from working journalists. Thus, the roles that journalists fulfill, both intentionally and subconsciously, became the focus of the primary research question. The secondary research question addresses their experiences and intentions during the reporting process and contextualizes these within the \#MeToo movement.

$R Q 1$ : What roles do journalists fulfill in covering sexual violence?

$R Q 2$ : How do journalists describe their experiences and goals during this process, particularly after the \#MeToo movement? 


\section{Chapter 3: Methods}

In seeking to understand how journalists view their roles as communicators of sexual violence, twelve journalists from North American news organizations were interviewed. These journalists are currently working in the field and producing content related to or involving sexual assault or sexual violence. All have produced some form of news dealing with the topic of sexual violence since the October 5, 2017, publication of The New York Times article on Harvey Weinstein. A Google search was used to find potential interviewees, their recent work, and their contact information. In order to find journalists who have produced relevant work within the appropriate time period, the search was restricted to the News tab with the following search terms: "rape," "sodomy," “domestic violence," "sexual assault," "sexual harassment," "sexual violence," and “sexual abuse." Using email and Twitter's private message system, 78 journalists were invited to participate. This number was ultimately determined by creating a list of the journalists' whose work appeared using the aforementioned search until less than half of the articles appearing on a page of results were relevant to this study. Eighteen responded that they were willing to be interviewed, and twelve ultimately participated in telephone interviews. Many who declined to be interviewed said that, despite covering sexual violence stories in the context of court reporting, they did not feel qualified to participate in the study. The researcher assured them that all levels of experience, depth, and breadth in reporting on sexual violence were important to the formation of meaningful results, but they still declined. This barrier, the niche that sexual violence reporting fills, and the nature of in-depth interviews led to a smaller sample. Similar studies using in-depth 
interviews have used comparable sample sizes in the low- to mid-teens (Tandoc \& Peters, 2015; Coleman et al., 2018; Hinnant, Jenkins, \& Subramanian, 2016; Lecheler \& Hinrichsen, 2010).

\section{Interview design}

While textual or content analysis may seem to be the natural choice for viewing how sexual violence is covered in the post-Weinstein era, this alone ignores the broader issue of how journalists are involved in that cultural conversation and understanding. Interviews are key in understanding the individual decision-making processes employed by reporters, editors, and teams. Not all journalists make these decisions the same way, nor are all affected by them in the same way. Interviews were conducted over the phone due to the wide range of geographic locations, time zones, and schedules specific to the different interviewees. These interviews were structured around several primary questions (see Appendix A) but allowed for natural discussion flow with the interview subjects and typically lasted between 20 and 45 minutes. The sample was varied by age, experience, reporting beat, and gender. Interviewees ranged from recent college graduates to journalists who have been working for nearly four decades. Because of the range of experience, the sample offers both journalists for whom the concepts enumerated under the \#MeToo movement are novel and those for whom they are familiar. Demographic diversity through the lens of gender accounts best for feminist concerns regarding how patriarchal standards may influence the way in which journalists view sexual violence. Of those interviewed, four identified as male and eight identified as female. Seven of the interviewed journalists were white, three were African American, 
and two were Hispanic. By ensuring that the sample included journalists from different beats or with different focuses, this study includes journalists who may have anticipated covering these issues, as well as those who did not. Interviewees included journalists who cover crime, breaking news, sexual violence, and education. These journalists worked at twelve different outlets in nine different states or territories. Though the original list of journalists contacted included those working across five continents, all of the journalists who ultimately agreed to be interviewed were based in North America. The sample included broadcast, print, online, and photojournalists. Of the twelve journalists interviewed for this study, none had been reporting on issues explicitly related to sexual violence for longer than seven years. One-third have been reporting on this subject for less than two years. Because the sample makeup was dependent on voluntary response, model diversity could not be guaranteed, but this sample is relatively diverse in terms of race and gender, so this is important to note.

JOURNALISTS' DEMOGRAPHIC INFORMATION

\begin{tabular}{|c|c|c|c|c|c|c|c|c|}
\hline ID & GENDER & RACE & FOCUS & ID & GENDER & RACE & FOCUS \\
\hline A & Male & White & $\begin{array}{c}\text { General } \\
\text { assignment }\end{array}$ & G & Female & African American & Photojournalism \\
\hline B & Male & White & Breaking news & H & Female & White & Sexual violence \\
\hline C & Female & White & Education & I & Male & African American & Breaking news \\
\hline D & Female & White & $\begin{array}{c}\text { General } \\
\text { assignment }\end{array}$ & J & Female & Hispanic & Crime/courts \\
\hline E & Female & Hispanic & Crime/courts & K & Female & White & Crime/courts \\
\hline F & Female & African American & Breaking news & L & Male & White & Crime/courts \\
\hline
\end{tabular}

In completing analyses of these interviews, this study uses the constant comparative method, referring interviewees' answers to the context of feminist theory on sexual violence (Glaser and Strauss, 1967). Interviews were coded through basic 
notetaking while reading through the transcripts, followed by searching for more subjectspecific answers. In the interest of comparing answers specific to the initial questions, all twelve interviews were transcribed and then searched for the following keywords:

"victim," "survivor," "alleged," "editor," "trauma," "mentor," "training," "language," "policy," "legal," "MeToo," "verify," and "goal." These are based on notes taken by the researcher during the interviewing process. Though not seen by the researcher in any of the literature or studies informing this thesis, it is a coding tool the researcher has used in previous transcription work. Most of the analysis of these interviews consisted of comparing journalists' individual answers to the priorities laid out for the role categorizations used in this study.

Because of the nature of conducting multiple in-depth interviews, interviews evolved as the study progressed, meaning that the first interviewee did not have precisely the same experience as the last (Fontana \& Frey, 1994). For this reason, it was essential that the researcher approach all interviews with a fresh slate and with an understanding that the individual being interviewed might not be willing or able to touch on the same subjects as another interview subject. Structuring all interviews around the same core group of questions (Appendix B) was essential to producing reliable and meaningful results despite any variations in response. Some changes did occur over the course of this study, primarily concerning follow-up questions and the wording of some initial questions. Though these changes did not fundamentally alter the nature or structure of these interviews, they are notable enough to mention before analyzing the results of these interviews. The phrase "sexual assault" was replaced with "sexual violence" in the initial questions to account for the fact that the subject matter of stories might differ and not 
focus specifically on assault. When asking about language-based decision-making, the issues of "victim" or "survivor" and the use of the word "alleged" were only used as examples if the interviewee did not appear to have specific examples that they wanted to discuss from the start of their answer. If these two issues in particular were not notable to the journalist, that in itself is a point of interest. The question of what an individual journalist thought was the ultimate goal of reporting on sexual violence was not included in the initial list of questions, though it was a subject that was touched on to some degree in the first few interviews. For this reason, it was formally incorporated into the list of questions. When determining journalistic role conceptions, it is helpful to have a question that asks those journalists to lay out their priorities explicitly, despite how obvious or odd asking the question might feel.

As with any interview process, there are ethical concerns within the live interview situation and at all stages of research. The issue of informed consent requires that any attempt to reach out to journalists as potential interview subjects include a sufficient explanation of the subject matter to be addressed. A part of that discussion included confidentiality. The researcher made an offer of confidentiality for all interview subjects for the sake of increased comfort discussing newsroom dynamics in the decision-making process. Journalists in this study are referred to using gender neutral pronouns and monikers such as Journalist A, B, C, etc. to maintain that confidentiality. Places of study and employment have been redacted from transcripts and are not included in the analysis of results. It should also be noted that names of story characters brought up by interview subjects during interviews are not included in transcripts or answers included in this study, as these individuals did not consent to the use of their identities for this project. 
The design of this research is not flawless. As with any interview process, there is a concern with credibility and ambiguity (Fontana \& Frey, 1994). How journalists answer these questions is not necessarily directly representative of how they go about covering sexual violence on a daily basis. This is not to say that they are lying or being intentionally misleading, but rather that they might perceive their actions in a more positive or negative light than reality. In addition, some interview subjects may not present a clear distinction between their own decision-making process and the team decision-making process due to the dynamics of their newsroom. However, due to the likelihood of conscious decision-making following the acceleration of the \#MeToo movement, this research design is the best suited to helping journalists and journalism educators understand how decisions are made in the coverage of sexual violence. While intent does not excuse any missteps or errors on the part of the journalists producing these stories, it helps to contextualize the mindset of the industry for the sake of providing realistic solutions for future journalists.

\section{Trauma in participants}

Because of the sensitivity of the issue being discussed and the personal connections that interview subjects may have with the subject matter, transparency and compassion during the interview process is key. It is not entirely unlikely that some of the journalists being interviewed have experienced sexual violence of some sort or are close to someone who has experienced sexual violence, so these interactions needed to be handled with great care and understanding, even if these interactions were never directly addressed. While some mentions of personal trauma did arise during the interview 
process, none of the interviewed journalists chose to elaborate further, and the researcher did not ask for further details once the topic had passed. The very tenets of trauma reporting that interview subjects were asked about needed to be applied in the interviews involved in this study - primarily allowing the individual to have control and respecting boundaries for the purpose of not retraumatizing the individual.

Whether or not to directly ask interviewees about whether they had had a personal experience with sexual violence was a point of personal contention. It is a subject that is private and that no individual should feel pressured to discuss for any reason. At the same time, personal traumatic events change how we look at the trauma that others experience. An individual does not have to experience sexual violence for themselves in order to empathize with and be supportive of a survivor, but someone who has might approach the process of interviewing and writing about survivors differently. To refrain from crossing a line, interviewees were not asked if they had experienced sexual violence. However, future studies might consider what benefits arise from treating survivor-journalists as experts on sexual violence reporting and supporting systems that enable them to tackle those projects, rather than assuming that it is a subject best left untouched. 


\section{Chapter 4: Results}

In order to answer the question of how journalists describe their experiences covering sexual violence, I begin by reviewing how they discover or are assigned their stories. I then discuss journalists' experiences with training specific to trauma journalism, including mentorship and contact with resources that provided an outside-the-newsroom perspective. I discuss their conversations with editors, followed by how these journalists viewed gender as influential in the reporting and editing processes for these stories. Next is a discussion of language in stories, focusing on victim/survivor, naming, and the use of "alleged." The next section focuses on framing and interviewing strategies, followed by a discussion of balancing journalistic expectations and empathy for survivors. From here, discussion transitions to the journalists' goals in reporting on sexual violence and how this aligns with the roles they attempt to fulfill.

For the most part, the journalists in this study came across stories about sexual violence through crime reports, court reporting, and breaking news stories. Only oneJournalist $\mathrm{F}$ - mentioned using social media in passing, noting that they sometimes found stories while "just kind of surfing." When stories are discovered in this manner, it is more likely that they will fall into the 88 percent of stories that McDonald and Charlesworth (2012) warned would frame events as individual rather than within a broader social issue. This is because it is more difficult to come into contact with survivors, whether due to a lack of information provided by law enforcement agencies or a newsroom standard of relegating sexual violence stories just to crime reporting. Several journalists experienced sexual violence survivors reaching out and asking for their stories to be told, either 
through general tip submission forms on news organizations' websites or by contacting them directly after the journalist published another story on the topic. Journalist B said they primarily received leads on more in-depth stories when survivors reached out after a typical court reporting story:

Typically, it's I publish something for a police report or et cetera, they reach out to me and they say, "Hey, I was this person. I'd like to tell my story." Or something along those lines, whether it's on the record or off record.

Regardless of how journalists receive these stories, preparing to discuss a personal and private event with a survivor requires a level of familiarity with how to deal with survivors of trauma. A journalist who is not seeking out these stories, but is instead assigned them or has a survivor initiate contact, might not be as prepared as one who was actively searching for them.

Most of the journalists interviewed did not receive any training, either during their college education or while working in newsrooms, that was intended to prepare them for covering sexual violence or traumatic events in general. All spoke of learn-as-you-go or on-the-job training mentalities in their newsrooms when it came to covering traumatic events. In the case of Journalist G, although their career has so far spanned more than 30 years in total, the story through which they were located for this study was the first story they worked on which dealt with a survivor of sexual violence. That led to some frustration during the reporting process: "I really wanted to protect (the survivor) and because I don't do this type of reporting, I wasn't always equipped with the right answers - all the right questions, I should say.” A few had fellow journalists, either at their news organizations or that they met through educational avenues, that they considered informal 
teachers that were crucial to their development as journalists covering traumatic events, but none were ever assigned formal mentors during the course of their education or reporting. Journalist $\mathrm{J}$, for example, had a mentor from graduate school that they kept in touch with:

When I was in graduate school, I had a mentor - or she's still my mentor. She works as a reporter now, and she taught me how to, if I wanted to do sexual assault reporting and if I wanted to do court cases specifically that focused on sexual assault, how to contact these women, how to be patient. I think that I came from an environment where I was obviously sympathetic, but I needed something fast and that is not what sexual assault reporting is. I think that she really taught me how to be slower, how to take your time and listen a little bit more.

Journalist $\mathrm{J}$ raises a concern that is not uncommon in reporting on sexual violence: how to slow down and listen when you are under a deadline. Especially in breaking news, journalists are asked to turn around stories quickly and accurately. When dealing with sources who have experienced trauma, there is the added factor of needing to ensure that a journalist is not rushing through an interview for the sake of their copy. Because of the emotional and physical stress that the survivor might experience by reliving their trauma for an interview, responsibility falls on the journalist to work in a way that might seem counter to their training. Other journalists cited online webinars through institutions like Poynter or documents produced by groups like Femifesto as resources that taught them the basics of reporting on trauma and sexual violence. Journalist L, for example, sought out online webinars on their own and at the direction of editors: "I was definitely encouraged to find those sorts of resources and there's been a lot of conversation with 
editors, about how we approach that coverage." Some, like Journalist D, were familiar with feminist theory or scholarly research on sexual violence: "I typically come to my job with feminist leanings so I felt like I had a pretty good handle on it but no one else in the newsroom, I think, was really thinking about it." Though these journalists briefly highlighted the influence of feminism in their understanding of sexual violence, it was not a point that they focused on due to peers and coworkers not having the same levels familiarity or experience. Journalists who did have additional knowledge on these subjects said they were more than happy to educate their peers on subjects related to their expertise. As Journalist K, who had earned their juris doctorate prior to reporting on sexual violence, put it:

One thing I can do because I do have that legal training is I can pick apart why a lawyer might be saying something or arguing a certain point or asking certain questions. Because I know what they're trying to get to with the legal standard to convict or to provide reasonable doubt and get their client off. So that's something I can do. And I do try to explain to other reporters if I'm in a situation where they look like they're, you know, getting upset - particularly, female reporters who may have sat through graphic rape trials. I do try to explain that to them - that it's all about legal standard and it's not somebody being cruel or evil.

Despite a lack of a formal mentorship system, none of the interviewed journalists said they felt like they were totally alone in the reporting process because of guidance provided by peers or during conversations with editors. Some did express frustration with a lack of formal training, however. When asked if they had received trauma-specific training, Journalist E said: 
I didn't. And that's something that I'm kind of upset about. I wish I had received more training on how to do this. A lot of my experience on decision-making has come from talking to other crime reporters and reading a lot on Poynter and (the Society of Professional Journalists) and kind of those resources to try to educate myself on the right way, if there is a right way, to report on sexual violence or crime.

Journalist $\mathrm{F}$ was on a similar page, particularly regarding training in higher education. During their time at university, they did not receive any training specific to trauma reporting. They said:

I graduated from college over three years ago, so I don't know if that's something that's being taught now in journalism school, but I definitely think it should be. Because, I mean, it's important for reporters to understand the seriousness of these stories and the magnitude, and the influence that you have as a reporter putting that information out there.

A lack of formal training on covering trauma, particularly sexual violence, is understandably frustrating for the journalists who are reporting these stories. Though some might be in a position where they feel comfortable approaching an editor or mentor who is knowledgeable about the issue, not every journalist will be in a position to do so. Given Harrington's (2018) assertion that news has been the slowest form of media to adapt in response to feminist critique of its handling of sexual violence, the lack of a formal structure for training on trauma coverage in general and sexual violence in particular makes sense. An institution can only change, after all, if its everyday participants actively seek and receive education that enables them to keep up. 
Regardless of the individual journalist's level of experience reporting on sexual violence, they cited conversations with editors as a key asset in confronting the challenges of covering this subject. Four journalists addressed the particular influence of male and female editors on their reporting processes. Journalist $\mathrm{J}$ said their experiences working on sexual violence stories for female and male editors had been notably different, with the latter requiring "a lot more work." They said a woman editor or reporter would be more understanding of some aspects of a survivor's story:

Especially in the news industry and the entertainment industry, you can find yourself in situations that you probably wouldn't have otherwise in the name of getting the story, making a connection, whatever, and I think that unfortunately it mostly applies to women to be put on these really uncomfortable situations. And I think sometimes, males in this industry or any industry that requires work being your persona ... they don't really understand that as much. So little things, like, how did she get into this hotel room late at night? That makes no sense. I think a woman editor or woman reporter is a lot more sympathetic to, "Oh, that could definitely happen.” As opposed to a man who's like, "Why would I ever go there? That makes no sense."

Journalist $\mathrm{F}$ had not worked with male editors on stories about sexual violence, but they expressed worries similar to what Journalist J had experienced, saying, "My current boss and my old boss were both women, so that could have had an impact on how we handle things. I don't know, maybe a man in charge might not have been as sensitive to some of those things." Journalist G had worked only with male editors throughout the course of 
reporting on sexual violence, but said they thought female editors might have placed a higher priority on these stories:

There aren't many women editors in our industry or at this particular newspaper. And I often wondered if we had more women in more powerful positions or any position if we could have gotten the story probably sooner than it was. Because there was a time where it sat for like six months, and nobody was reading it. And don't get me wrong - the editors who added to my story were all male, and they all had wonderful insights and opinions about how I could make it better and everything ... But I also often wonder if we'd had more women in leadership roles, if we could have got to publish sooner.

Unlike journalists $\mathrm{G}$ and J's experiences, which highlighted a divide in comfort and communication with male and female editors, Journalist A's experience with male and female editors was more collaborative. Journalist A's managing editor - a man suggested reaching out to a female colleague at a nearby news organization, since only men had looked over the story in question. A female editor, Journalist A said, might see something "obvious and apparent to a woman" that other eyes might have missed. Boyle (2012) addressed concerns about the male perspective that news coverage typically embodies, lending credence to the concerns of journalists $\mathrm{G}$ and J. Just as sexual violence is a gendered offense, journalism is an institution that feminist scholars assert is subject to gendered dynamics and frames. Though experiences of sexual violence are not exclusive to women, the gendered nature of the offense and the power dynamics involved lend credence to these journalists' concerns about the gender of their editors. 


\section{Language in reporting on sexual violence}

For those journalists who did feel comfortable turning to editors for nuanced advice on these stories, most conversations - and most of the challenges raised regarding sexual violence coverage, in general - centered on language-based decisions. Journalist B relayed their own experience with the importance of careful language choice:

It can be very easy to soften accusations based off of the legal language ... like somebody's trying to meet up with the juvenile "for sex." That sentence alone is almost an oxymoron because the juvenile can never ... consent to having sex period, based just off the law. There's no situation where a (juvenile) can. You can't meet one of them for sex. That's inherently something illegal, and using the word "sex" in that situation misrepresents or makes it more casual.

A journalist might instead use terms including "statutory rape," "rape," or other language specific to the charges faced by the perpetrators. The phrase "nonconsensual sex" should not, however, be used in the place of "sex," as it implies that sex can occur without consent. Without consent, it is not sex; it is rape. That softening of accusations, Journalist B said, is dangerous: "(Sexual abuse is) the last thing you want to destigmatize." In addition to not destigmatizing sexual violence, journalists said they tried to refrain from sensationalizing it. The major consideration in pursuing this goal was how graphic descriptions were within stories. Journalist L said:

In conversation with my editors, we've made a really concerted effort not to include details that are overly graphic because we want to avoid sort of sensationalizing the coverage. Both for our readers, because we don't see that 
adds any value, and also to avoid trauma to people who may know about the situation.

The language that was best, then, was as Journalist L suggested: "Very specific but noninflammatory language." These journalists' concerns are central to addressing Easteal's (2014) assertion that sexual violence is about domination, not desire. Careful and intentional word choice is essential in conveying to audiences the power dynamics and motivations inherent in sexual violence. The three specific language concerns that interviewees identified focused on the use of "victim" versus "survivor," naming individuals, and using the word "alleged."

\section{Victim and survivor}

The journalists involved in this study tended to favor using the term "victim" when discussing individuals issuing accusations of sexual violence, both in their work and in interviews with the researcher. Across 12 interviews, the term "victim" was used 77 times, compared to just 54 uses of "survivor" (19 uses of "survivor" came from one interview). Several of the journalists in this sample who used the term "survivor" described experience dealing with the culture of sexual violence more directly, including working on long-term projects involving rape crisis centers or for collectives creating trauma reporting resources. Journalist $\mathrm{C}$ spoke to the director of a rape crisis center, who they said educated them about using the word "survivor:"

When I visited the rape crisis center, for the most recent story about how they stand up for victims, kind of that nonprofit profile, I talked (to the) executive director for a long time about that. She definitely said, you know, we prefer survivor, we don't like to say victim, you know? Survivor is more empowering." 
The journalists who preferred to use the term "victim" in their reporting cited style guidelines and standards related to crime reporting. As Journalist E noted, these individuals are victims of a crime, so referring to them as such is consistent with that focus. Still, Journalist E is not set on the use of the word "victim" in copy:

I use the word victim more often than not, just because they are the victim of that crime. But then at the same time I also struggle with using that word because then there's also kind of the connotations and kind of everything that comes with the word victim, you know?

As noted by Blanding (2017), using the word "victim" can imply a lack of agency on the part of the survivor. The most recent guidance (2018) from the Associated Press is not precise on which term is preferred, saying only that the terms should be handled "with care because they can be imprecise and politically and legally fraught." Journalist C compared the selection of "victim" - a language decision that they noted might seem cold - to the AP guideline for obituaries of using "died" rather than "passed away." Several journalists said that their decision to use either "victim" or "survivor" depended on the type of story being written. In a news brief, they would more likely use "victim," while they might use "survivor" in a feature story or profile (The very existence of features and profiles focused on survivors of sexual violence was something that interviewed journalists noted was a change from decades prior - this will be discussed in greater depth later). Journalist $\mathbf{J}$ said terminology was a decision that they ultimately left up to the individual whose story they were telling - if that person called themselves a survivor, then that is the word they would use in their copy. This journalist said that the primary reason for that practice is that identifying as a survivor is a type of progression 
with sexual violence trauma that not everyone has. Several journalists said they tried to find alternatives to both "victim" and survivor," whether that be terms like "accuser" or a moniker such as "the woman" or "the wife" that could be used without revealing identity.

\section{Whom to name}

The twelve journalists interviewed for this study all shared a similar stance regarding naming both survivors and perpetrators in stories of sexual violence. Most mentioned an explicit policy at their news organization that stated that the individual issuing an accusation in cases of sexual violence would not be named in the story unless that individual gave their explicit and willing consent to be named. Journalist B said this was the norm:

Ninety percent of the time, we are not (naming them), and if we are then it's very clear up front. In those cases, it's their decision, it's not our decision. Our publication does not publish alleged victims of sexual assaults under any circumstance unless they come forward and want to be named.

Some survivors may choose that anonymity or may be asked by family members or legal counsel to remain unnamed. Journalist E pointed out that the survivor does, however, have a right to be named if that is what they want, and that they believe it is the journalist's duty to make sure that the survivor can lay claim to that right:

I know with sexual violence it's this kind of standard practice not to name them, and I agree with that to protect their identity, but my thing is if they want to have a voice, it is absolutely their right to do so.

The cases that involve minors are the simplest in terms of deciding who to name, according to the interviewed journalists, because the default decision is to refrain from 
naming anyone to eliminate the risk of identifying the minor. Stories involving kids, in general, seemed to involve the easiest decisions for journalists. Journalist F discussed a story they wrote about a teacher accused of installing cameras to spy on students in a hotel during a school trip:

I stuck to the nuts and bolts of what happened in court in my reporting, and I instructed my photographer not to take a video of them crying when they came out of the courtroom, and I did not attempt to interview any of them about what happened because I don't feel like that's appropriate. So again it's a play-by-ear thing, but it's also a common sense thing as a human, in terms of how to handle sensitive situations like that as a journalist.

Whether or not the perpetrator is named represented a more complex issue. The decision of whether or not to name the perpetrator in cases of sexual violence came down to two primary considerations: whether identifying the perpetrator could lead to identification of the survivor and whether it could cause undue harm to someone who had not been criminally charged or convicted. In the case of the former, the main concern arose when the survivor of sexual violence was a family member of the perpetrator who could be identified based on their relationship with the individual whose name was used. Journalist F encountered such a case:

A wife accusing her husband of raping her, and I was very delicate with that, not to mention who she was or even him. I didn't reveal who he was, because if I did, people would know, oh that's so-and-so's husband, so we have to be careful about that because it's revealing 
Journalist L dealt with that concern, as well, in two separate stories. In both stories, the survivors remained unnamed. However, the naming of perpetrators brought about vastly different results. Journalist L said:

The victim (in the first story) did reach out to me afterwards to thank me for covering the story. So that's gratifying that perhaps my coverage did ... I'm not sure exactly how it benefited her, but it was nice that that coverage was appreciated. But another case where we named the perpetrator - alleged perpetrator - but not the victim, the family of the victim was very upset because it's a small town and many people knew who the victim was. And the family was concerned about stigmatization at school and ill effects, so definitely there's no one perfect solution.

If the story being told is from years prior and no charges were ever brought against the individual, naming them could lead to legal action being taken against the news organization depending on the other language used in the story. As Journalist B notes: The most important thing from our legal perspective, especially, is how we approach language regarding sexual assault, sexual violence, things along those lines. So typically these things involve charges. Which that makes it pretty simple, because then you have the language kind of laid out there for you with what ... the suspect is specifically charged with. When it comes to somebody who hasn't been charged is when it becomes more difficult. And that's where it's very, very case by case - in those situations. That depends on a million different variables on what we decide to do when somebody contacts us. 
Discussing accusations and charges was a point that all interviewed journalists raised before the question could be asked. As Journalist I put it:

I have to report what has happened, and so I cannot blatantly say this person is a rapist, this person has done this, this person is guilty of these crimes, because they haven't had their day in court yet. So who am I to say that they are the subject of sexual violence?

Naming an individual when they have not been charged or convicted can contribute to assigning guilt before the criminal justice system does - doing so can lead to libel charges. For this reason, these journalists were hesitant to name perpetrators. However, these individuals were not granted the same level of control as survivors. In the case of those who experienced sexual violence, it was ultimately their decision whether or not they would be named. These journalists agreed that perpetrators, alleged or convicted, should not be afforded the same influence.

\section{Using 'alleged'}

It is because of legal and accountability concerns that six of the journalists interviewed for this study said that using the word "alleged" in stories about sexual violence was necessary despite negative connotations that the word might have. Journalists B and D followed up by saying that they tried to avoid using "alleged," or used it as sparingly as possible, in order to avoid any stigma associated with the word. Journalist D said they often relied on attribution instead of the word "alleged," making it clear that any accusations of sexual violence were sourced to the individual issuing them:

Of course, the newsroom lawyer wants you to use it as much as possible in JSchool. To always err on the side of saying "alleged." But it's a loaded word. It 
casts doubt on the survivor. It makes survivors real uncomfortable to see that word as well, I've noticed. So even being able to say, she said, he said, rather than “alleged" because then you're still attributing it, makes a world of difference.

Others, like Journalist J, used both: "Unless someone has admitted to it or has been convicted of it, I don't like to use a straight sentence without the word 'alleged' or 'according to somebody."” Despite preferences for avoiding the word, some journalists still incorporated it into their work for the sake of legal security. Journalist D recounted conversations with their news organization's lawyer to ensure that any alternative methods did not imply guilt prior to a conviction:

He actually took out some of the "allegeds" that I had put in because I overdid it a little bit. That was really cool. Because, from my perspective, I don't want my company to get sued.... He was like, you can actually chill in a few of these spots, which is really cool to hear that he understood why it was important to me to use the right language.

In some cases, however, using terms like "alleged" and "accused" were journalists' best tools in discussing accusations to their full extent given legal restrictions. Journalist A, for example, works in a state where there is no charge for rape, so they have to find a different way to discuss rape accusations:

When you hear sexual assault, especially colloquially, in casual conversation ... that doesn't always mean rape to every single reader. But in (some states), that's the charge. You can just change it - you can make first degree sexual assault equals what a rape charge is. So when we were talking about the language of that story, we can't say "charged with rape" since technically that is inaccurate. But 
what we can say is that he is accused of rape - based off of every accusation that was in the warrants that was in this case, that's an accurate way to describe it. Saying that an individual is accused of rape allows for proper communication of the severity of the charge without outright assigning guilt. Some journalists pointed out that "alleged" carries more of a stigma than "accused," but that both are helpful in avoiding legal pitfalls in reporting.

\section{Framing stories}

Journalists tended to agree that creating a narrative that was centered within a broader conversation was essential to covering sexual violence, though it is important to note that this didn't always happen in the form of thematic framing. For some journalists covering specific cases of sexual violence, it was more important to consider the web of stories that can arise from what is seemingly a single incident. Journalist B noted:

In those cases where we have multiple different sides being presented, the best case typically is to lead with the neutral fact of an arrest - whatever has taken place on paper - and then going into both sides based off of the flow of the story and where things are going. And that's sometimes mitigated by this information coming out not all the same time, by there being a timeline, which kind of allows us to, in multiple follow up stories, be able to cover these different angles and to be able to present them all in a way that we hope our readers understand the bigger context of these three stories.

Journalist B said that digital media was particularly helpful to them in creating comprehensive, connected stories: "Online, we can individually present each puzzle piece 
as it comes out." In these cases, the journalists are using episodic framing, but they are doing so in a way that ensures readers understand the depth and breadth of what is seemingly a single incident. The other common approach that journalists discussed was seeking out national stories or trends and localizing them. These journalists made these stories more relevant to their readers by seeking out experts in the community or finding timely cases that were representative of the issue. Journalist F, in particular, was a proponent of this type of coverage:

I did a story about sexual assault in the military, and there was an article that I found that was pertaining to something that happened somewhere else, but I localized it. And I talked to some local officials in our area about how that works and kind of a lot of the misconceptions when it comes to military sexual assault. It's just having my eye open to things that are going on, regardless of where they are, and then my goal is always to try to bring it back to our local area for our viewers to be able to relate to it.

Overall, there was no one method of framing that the interviewed journalists turned to for stories on sexual violence. Like many of the decisions made during the writing process, it was a case-by-case process that depended on the sort of article being written. A profile of a survivor, for example, would be easier to contextualize within the scope of the \#MeToo movement than a news brief about an arrest or charge for domestic violence. The journalists recognized that many of their choices were limited by expected structures of stories. For the most part, the framing decisions described by the journalists were contrary to notions of journalists' tendency to treat stories as isolated incidents. However, 
the chosen frames were more focused on contextualization within a community than within the problem of social male dominance with which Easteal (2014) was concerned.

\section{Methods for interviewing survivors}

Several journalists had never sat down with a survivor of sexual violence for an interview. Their stories had been based solely on documents, court proceedings, and accounts from law enforcement. Journalist L was one such journalist. They said, "Almost all of the coverage has been dealing with court documents. I have not sat down with any

of the victims that I have written about here.” Journalist F said that, although they had not interviewed a survivor, they still took certain precautions when interviewing authorities:

Personally for me, it is a challenge even if I'm just interviewing law enforcement about something, because I'm a human even though I'm recording the news. And I'm thinking, you know, this could have been me, this could've been my mother, this could've been my sister, so I do think personally it does influence my questions and the way that I ask my questions. ... I care. I'm very careful with asking questions that I don't think add anything to the story. If it's just something that's going to come off as me being nosy or, like I said, the answer is going to in some way put the victim in a situation where they're being hurt again by my reporting, then I don't do it.

Among the considerations that all interviewees thought were important during the reporting process, avoiding retraumatizing or revictimizing survivors was an explicit priority for a majority of them. Those who did not address this priority had not had any experience interviewing survivors, instead basing their reporting on documents and 
conversations with law enforcement or other authority figures. Those journalists who did discuss the importance of avoiding retraumatization focused primarily on the importance of granting the survivor some semblance of control. Journalist $\mathrm{H}$ noted the importance of doing this for trauma survivors:

Trauma is ... losing control, whether that's actual or perceived. This profoundly disturbing event that they've experienced comes with a lack of control, and so I start to ask myself in my reporting methodology, what am I doing as a journalist where I am either giving them some control and still doing it ethically, or retaining it for myself and making it another negative experience for them? My story can either become part of their traumatic experience - they're rehashing it. It could be like worst case, like retraumatizing or something that they deeply regret, or, best case scenario, it actually becomes part of the way that they heal or part of their healing process because it gives them a little bit of an opportunity to regain power and agency by telling their story.

Methods for this included: allowing the survivor to pick the location of the interview, granting the survivor permission to stop the interview at any time, and allowing the survivor to see relevant parts of the story prior to publication. Journalist $\mathbf{J}$ said they tried to allow the survivor to act as the authority on the subject:

I think in sexual assault reporting, playing a little dumb gives survivors the confidence to talk about what they're talking about because they have an authority on it and they're also educating, which kind of just shifts the narrative from them being a victim to them trying to tell a story or having authority on the subject. 
Some journalists granted survivors more leeway with their ability to backout of stories. Journalist E said that if a survivor did an on-record interview and changed their mind after, they would "nix it" as a means of providing control to that individual. Journalist D said they would not allow the survivor to retract statements, but that they would allow them to correct things:

I'll call them and read out a quote I use in the story to them or a fact in the story and just get them to confirm that that's what they meant. I'm not like giving them a chance to retract something on the record or anything like that. I'm making sure that everything is correct because, when you're talking about trauma, sometimes your memory isn't perfect or things get emotional, and that allows some sort of second chance to just think about those things. Because when you're in the middle of an interview and you're recalling trauma, things can get messy, you know? And it just gives them like a chance to think about it.

Supporting survivors through the reporting process was a priority for every journalist interviewed for this study, regardless of their level of familiarity with specific methods recommended for trauma reporting. Journalist I summed it up as such:

Of course, there are strategies, but for me, I feel like it's more of just being a decent human being. I feel like it's just going into a situation knowing this person lost someone or this terrible thing happened to this person. You just have to go into the situation like you're going into a funeral or like the way that you talk to your friend when they're going through something. You try to get them through it - it's the same way you have to do it when you're reporting. 
Though journalists should be mindful that they are not crossing lines (whether professional or personal) while supporting survivors, being emotionally open and supportive of the person who has experienced a traumatic event is something that all the journalists agreed on.

\section{Being a journalist versus being human}

Balancing that support with the professional duties of a journalist - primarily the goals of remaining objective and prioritizing verification - was a challenge that interviewees had mixed responses to. Several simplified the issue to a matter of verification - if court documents or other hard evidence backed up the survivor's story, then they posited it was a matter of attributing information appropriately and allowing the evidence to speak for itself. Journalist K said that they only included attorneys' arguments if they were "reasonable." For example, justification of sexual violence based on the survivor enjoying rough sex would not be included in their story. Journalist $\mathrm{H}$ noted that the activist mantra "believe all women" does not work for journalists, and that journalists should instead listen to all survivors who come forward and subject their statements to the same verification processes that they would use for any other story. Journalist $\mathrm{J}$ noted that false reports do sometimes happen, but it is the job of journalists to do their due diligence in performing verification methods:

We've all been burned on a story. I had a story that I was working on with a woman for maybe months before she actually told me she didn't mean it. And obviously The Rolling Stone article is enough to give us all pause and make us a little bit wary of putting all of our eggs in just one woman's pail. I think that it's 
really hard to not see both sides. Like The New York Times did it correctly, Rolling Stone didn't.

Journalist J is referencing Rolling Stone's failure to subject their story to proper verification methods and contrasting it to the work done by Kantor and Twohey in reporting on Harvey Weinstein. Performing verification and exercising scrutiny, they are saying, is key to making sure that the stories released to the world are true and verifiable and do not undermine the credibility of sexual violence survivors in the long run.

Making sure they have a solid story, Journalist $\mathbf{J}$ said, is something that journalists should be doing when reporting on sexual violence anyway: "I don't think it would do (survivors) justice if we badly reported a story that could be turned around and have some sort of backlash for them." Regardless of their methodology, however, all of the journalists interviewed touched on one common point: being human. Journalist $\mathrm{C}$ stressed that journalists who care about those affected by their work were not inherently violating standards of professionalism:

It's okay to care. You can care but you can put your feelings, kind of - just don't let your feelings guide your storytelling, let the facts guide it, right? You can have feelings, just don't let that be what guides things all the time when you're writing and reporting a story.

Journalist $\mathrm{C}$ said that, in caring about the individuals they interview, they also need to be mindful of how it emotionally impacts the journalist:

Most of my interviews have been over the phone, and I think because they can't see me, I have cried a little bit. Like, I don't know, not where I'm like blubbering and obviously crying, but a few tears shed, and I try to keep it together when I 
talk to them, because it's sad to hear. And I think that if I were in person, I would definitely not do that, but because they can't see me on the phone, I let it come out just a teeny bit. But I don't want them to think I'm crying for them. I still try to just have a conversation with them, be human, but I don't want them to know that I'm crying like that.

Feeling empathy or sadness for survivors was a point that several journalists raised, though they all said they tried their best to conceal physical manifestations like tears out of concern that the survivor would think they were being pitied. For Journalist H, being human extended beyond interactions with the survivor:

On the flip side, when I'm interviewing perpetrators or accused, it's honestly harder, if I'm being frank, but I try to do some of the same things - not as far as giving back control, but first trying to be a human and listening to them as a human. And often how you get the best quotes is connecting with them, anyway. For others, being human meant tapping into their own experiences in order to empathize with the survivor or other sources. Journalist E said:

I have a history of trauma and mental health stuff, so I also think of how I would want to be treated in that situation, if I were on the other sitting at the other end of the table, or so to say. Like if I was in their shoes, how I would want to be treated. ${ }^{1}$

Regardless of whether or not they had or communicated personal experience with trauma and mental illness, journalists expressed a wariness to cross lines or overstep personal

\footnotetext{
${ }^{1}$ Journalist $\mathrm{E}$ and the researcher did not discuss the interviewee's history of trauma and mental illness beyond this point. The interviewee did not specify whether their trauma was related to an experience with sexual violence.
} 
and professional boundaries. They conveyed feeling that - despite their obligations to their jobs - it was not necessarily their place to ask some questions about such a personal event. Journalist B said:

These are obviously difficult conversations and are typically graphic in nature. And it's often difficult for me as a reporter because all this stuff is almost stuff that I shouldn't know or shouldn't be hearing from a certain extent, because all very private ... obviously this is one of the most traumatic moments in somebody's life that they are opening up, being vulnerable, and sharing with you. And that's kind of a difficult situation to be in, because, as much as getting the story is important, you never want to take advantage of somebody that's in a place like that, in an emotional vulnerability.

Some journalists conveyed a level of discomfort with violating norms of objectivity that demand a journalist stay detached from their work and not emotionally invest in the subject, but ultimately the goal of human connection with survivors won out. In the case of Journalist F, their identity - importantly, their shared identity with some interviewed survivors - meant more than a norm:

As a journalist my opinion doesn't matter when I'm reporting the facts about something. But as a woman - and I'm an African American woman - I do take pride in sharing stories that are bringing attention to topics and issues that may have been uncomfortable for us to talk about or see in the news a couple decades ago. So I think these stories are important to tell, and bringing attention to things that are going on on a deeper level is something that needs to continue to be done, because I do think on a larger scale it does have an impact. 
A journalist's identity can serve as a connection point with survivors or imbue them with knowledge that another reporter would not have because of their position in life. Connecting on a human level based on a common identity can enable journalists to tap into dynamics in sexual violence beyond gendered or class power imbalances, including those related to race, sexuality, religion, age, and other factors.

\section{The goal of reporting on sexual violence}

The journalists interviewed for this study had different ideas about what the ultimate goal of reporting on sexual violence is or should be, which ultimately led them to fulfill different journalistic roles in their reporting. Because the goal of reporting on sexual violence aligns closely with the role a journalist is trying to fulfill, these two aspects will be addressed concurrently. Following the completion of the twelve interviews, and using all of the data enumerated above, the four roles adapted from Christians et al. (2009) and outlined in the literature review - monitorial, radical, interpretive, and humanistic - could be more precisely defined (Figure 1).

The four roles differ in terms of their basic doctrines, common language decisions, perceived role of \#MeToo, journalist's relationship with the survivor, and the ultimate goal of reporting on sexual violence. It should be made clear that none of the twelve interviewed journalists fits perfectly within the confines of any of the four established roles, but they serve as guides for journalists' behavior and choices when reporting on sexual violence. Among the journalists in this sample, all four roles were represented, though the radical role was significantly less present. The journalists interviewed for this project expressed priorities and reporting strategies that aligned most 
closely with the monitorial and interpretive roles, though elements of the humanistic role were tightly intertwined with those presented under the umbrella of the interpretive role.

\section{FOUR ROLES IN REPORTING ON SEXUAL VIOLENCE POST-WEINSTEIN}

\begin{tabular}{|c|c|c|c|c|}
\hline & Monitorial & Radical & Interpretive & Humanistic \\
\hline $\begin{array}{c}\text { Basic } \\
\text { doctrine }\end{array}$ & $\begin{array}{l}\text { A watchdog on all } \\
\text { forms of power and } \\
\text { authority (i.e., a } \\
\text { government body or } \\
\text { other dominant group). } \\
\text { Journalists monitor } \\
\text { justice systems or } \\
\text { perpetrators. }\end{array}$ & $\begin{array}{l}\text { Promoting views } \\
\text { outside the mainstream } \\
\text { for progressive social } \\
\text { change. Journalists } \\
\text { advocate for end to } \\
\text { rape culture and } \\
\text { changes to justice } \\
\text { systems. }\end{array}$ & $\begin{array}{l}\text { The media facilitate } \\
\text { conversation while } \\
\text { interpreting discourse } \\
\text { for the public. } \\
\text { Journalists would } \\
\text { encourage public } \\
\text { conversation around } \\
\text { sexual violence. }\end{array}$ & $\begin{array}{l}\text { Enriching lives and } \\
\text { unpacking meanings. } \\
\text { Journalists focus on the } \\
\text { individuals and second } \\
\text { and third acts of trauma } \\
\text { reporting (resilience } \\
\text { and search for } \\
\text { meaning). }\end{array}$ \\
\hline $\begin{array}{l}\text { Common } \\
\text { language } \\
\text { decisions }\end{array}$ & $\begin{array}{l}\text { - "alleged" as a } \\
\text { necessity } \\
\text { - "victim" is the } \\
\text { preferred term } \\
\text { - only name survivor if } \\
\text { they want to be named; } \\
\text { name perpetrator if } \\
\text { possible }\end{array}$ & $\begin{array}{l}\text { - minimal use of } \\
\text { "alleged" } \\
\text { - allow the survivor to } \\
\text { choose terminology } \\
\text { - only name survivor if } \\
\text { they want to be named; } \\
\text { name perpetrator if } \\
\text { possible }\end{array}$ & $\begin{array}{l}\text { - use "alleged" when } \\
\text { necessary } \\
\text { - terminology based on } \\
\text { context } \\
\text { - only name survivor if } \\
\text { they want to be named; } \\
\text { name perpetrator if } \\
\text { possible }\end{array}$ & $\begin{array}{l}\text { - use "alleged" when } \\
\text { necessary } \\
\text { - allow the survivor to } \\
\text { choose terminology } \\
\text { - only name survivor if } \\
\text { they want to be named; } \\
\text { name perpetrator if } \\
\text { possible }\end{array}$ \\
\hline $\begin{array}{c}\text { Role of } \\
\text { \#MeToo }\end{array}$ & $\begin{array}{l}\text { Sets a precedent for } \\
\text { journalism that could } \\
\text { hold perpetrators and } \\
\text { systemic enablers } \\
\text { accountable. }\end{array}$ & $\begin{array}{l}\text { Creates a means for } \\
\text { dismantling and } \\
\text { combatting rape culture } \\
\text { and the systems that } \\
\text { allow those ideas to } \\
\text { persist. }\end{array}$ & $\begin{array}{l}\text { Creates a cultural } \\
\text { conversation that } \\
\text { journalists can } \\
\text { participate in by } \\
\text { continuing to tell } \\
\text { stories of survivors. }\end{array}$ & $\begin{array}{l}\text { Provides support for } \\
\text { survivors, creating a } \\
\text { culture in which they } \\
\text { feel empowered to } \\
\text { come forward and share } \\
\text { their stories. }\end{array}$ \\
\hline $\begin{array}{l}\text { Relationship } \\
\text { with survivor }\end{array}$ & $\begin{array}{l}\text { Limited to the duration } \\
\text { of the reporting } \\
\text { process. }\end{array}$ & $\begin{array}{l}\text { Stay in contact with } \\
\text { survivors as long as is } \\
\text { mutually appropriate. }\end{array}$ & $\begin{array}{l}\text { Limited primarily to } \\
\text { the reporting process; } \\
\text { some contact after. }\end{array}$ & $\begin{array}{l}\text { Stay in contact with } \\
\text { survivors as long as is } \\
\text { mutually appropriate. }\end{array}$ \\
\hline Ultimate goal & $\begin{array}{l}\text { Hold perpetrators } \\
\text { accountable and make } \\
\text { the public aware. }\end{array}$ & $\begin{array}{l}\text { Work to undermine } \\
\text { patriarchal systems that } \\
\text { silence survivors. }\end{array}$ & $\begin{array}{l}\text { Bring community } \\
\text { together to discuss and } \\
\text { address problems. }\end{array}$ & $\begin{array}{l}\text { Empower survivors, } \\
\text { whether they choose to } \\
\text { share their story or not. }\end{array}$ \\
\hline
\end{tabular}

Figure 4

The goals that journalists expressed varied, but most focused in some capacity on justice for the survivor. Journalist J noted that part of achieving that justice is exposing the "ugly" and "scary" things in the world, and that reporting on sexual violence does just that. This view sits somewhere between the monitorial role and the radical role. It is worth noting that Journalist J's goal was expressed in a way more consistent with the 
radical role than other journalists who focused on exposure and accountability as their main priorities. Journalist $\mathrm{J}$ referenced the Weinstein case specifically:

Movies got screwed over, actresses got screwed over, franchises got screwed over, producers ... I mean, it only brings about more damage than probably good for some people and some people are upset, but our responsibility is to bring a voice to somebody or justice to a situation that probably wouldn't get it otherwise - to enact some sort of change whatever that may be. That sounds really righteous, but I don't know.

Journalist $\mathrm{J}$ discusses the journalistic responsibility to bring about change, specifically through granting voice and justice to the underrepresented and unheard. The radical role advocates for undermining existing power structures for the sake of radical change, which Journalist $\mathrm{J}$ invokes by focusing on those that the current justice system fails. Journalist F said their goal - specifically as a reporter - in writing about sexual violence is bringing attention to events and issues that would not have previously been considered newsworthy:

You know, people need to know these things. People need to know that women are getting sexually assaulted in the military. People need to know that wives can be raped by their husbands, that that is possible. ... It is bringing attention to what is happening, putting a light, shining a light on reality so that people can understand the magnitude of the situations and how impactful they are. Their personal goal, however, is to let survivors know that it is okay to come forward. Journalist F's personal goal within sexual violence reporting aligns best with the radical or interpretive roles, but what they called their "politically correct" goal better 
aligned with the monitorial and interpretive roles - it is simply to report the news and inform the public. In a role more closely aligned with the humanistic approach, Journalist D said the person they are most accountable to throughout the reporting process is the survivor. Journalist D elaborated:

This being some kind of catharsis or justice rather than making everything worse is my number one priority with that, what I care about most. And there are some people who, no matter how you report it, are never going to be supportive of survivors or will have that mentality that like they did something wrong or whatever. And I don't think it's my job necessarily to convince them. It's certainly not the survivors' job to convince them. That's not what we're doing. Again, these roles are not mutually exclusive, and that overlap adds to the complexity of the conversation of reporting on sexual violence. However, when assigned the role that best described their priorities, five journalists leaned monitorial, four leaned interpretive, one leaned radical, and two leaned humanistic. Journalist G's goal in reporting on sexual violence, for example, leaned particularly humanistic, focusing on empowering the survivor regardless of how much time has passed since the incident: "It's never ever too late to get help. It's never ever too late to let someone know. It's never too late to take back your power. It is never too late to do that." Some reporters had a harder time pinning down a specific goal. Journalist L struggled with weighing the risks associated with reporting on sexual violence:

How does coverage, particularly of sexual violence and domestic violence, how does that help the overall situation? On the one hand, it might be useful to report on as many cases possible in order to show people that it's a problem and 
highlight the problem, but when it comes to covering individual cases, obviously particularly of domestic violence, the coverage and the stigmatization can be sometimes worse than dealing with ... I don't want to say it's worse, but it can be an added trauma, and that's not that's not helpful to what we're trying to do.

Journalist $\mathrm{L}$ went on to describe an ideal role that sounded mostly interpretive - bringing attention to events and encouraging community discussion - but ultimately returned to the same point of uncertainty: "I'm not quite sure what the role should be. I think it's important but I'm still not quite sure what the true benefit should be.”

\section{What \#MeToo means for journalists}

In discussing how journalists describe their experiences and what roles they fulfill while pursuing their reporting goals, it is important to note what has changed. Are things any different after the accusations against Harvey Weinstein than they were before? The interviewed journalists were mostly optimistic about what a post-Weinstein reporting world could look like, especially given what changes have already occurred in the last decade (including prior to Weinstein). Journalist C notes:

In the newsroom, I feel like now it's a subject that can go on the front page and it won't be questioned anymore. It won't be like, "Oh, we shouldn't mention it. That's too, you know ... that's not important enough maybe to go on the front." But now it is important enough, and I think that's a good thing. I think that's a really good thing. Just kind of the way that it's risen in profile as an issue. It's something that matters. 
Others agreed, particularly noting that talking about sex and sexual violence in mainstream media has become less taboo. On the contrary, it has become something that readers are invested in and care about because it affects their communities. At the very least, these are the stories that they have come to expect, Journalist F said:

Since the \#MeToo movement kind of became what it is, any stories related to sexual assault, sexual violence, is something that viewers want to see, they want to hear about, they want to know about. And I think maybe ten years ago, it was a little more taboo than it is now, but it is much more acceptable. And I think viewers expect to hear the stories and know what's going on in their community as it pertains to these situations.

In addition to what steps post-Weinstein journalism has already made, one journalist in particular was hesitantly optimistic about what could follow. Journalist J reflected on the untouchability of some bigger names in the world, and how Weinstein served as an example of what was possible. They said:

There's people that, the longer that you do this, the more things you hear about people, big names in the industry - and in any industry - but also floating names around. And I think The New York Times' ability to actually dedicate so much time and do it is really inspiring for a lot of us that probably have a lot of names that we haven't touched. And should. And I think that it also set the precedent of what good journalism in this sense is.

Two journalists were less optimistic about the total effect of \#MeToo on the reporting climate - not because they didn't see it making a difference in many places, but because they had experience in areas where its influence wasn't felt. When asked whether 
they had noticed an effect from \#MeToo in their environment, Journalist E said, "Honestly no. I think maybe in other areas of the country it might have, but not for me ... there's not a lot of MeToo movement activity or any of that really going on where I've been reporting." They were not alone in seeing this lack of response. Journalist D noted that, at their previous newsroom, talking about issues in sexual violence or trauma reporting wasn't outright discouraged, but it was certainly a conversation that wasn't going to be had. They said:

It was kind of like it was just a ridiculous conversation to have. It wasn't something that anybody thought they had to talk about or that was worth discussing. Basically, it seemed like it was a ridiculous proposition to suggest that what we were doing wasn't great. I think that's more so what it is. And I want to have those conversations. That there are definitely people in the newsroom mostly are established, like dudes obviously, higher up editors - who I guess just didn't see a need to change anything.

Though all of the twelve journalists interviewed saw at least some positive impact from the \#MeToo movement on their own reporting or on the culture of journalism around them, the pockets of isolation that Journalists D and E discussed are noteworthy and should not be brushed aside. This will be discussed in slightly more depth in recommendations for future research. 


\section{Chapter 5: Conclusions}

\section{Discussion}

This research set out to answer two main questions: what are journalists' experiences and goals in covering sexual violence post-Weinstein and what roles do they fulfill in pursuing those goals? In thinking of sexual violence coverage, it is easy to think of two camps: those who work by the book, relying on court documents and authority figures above all else, and those who prioritize a fight for radical change across systems interacting with survivors. In speaking with the journalists who cover sexual violence, those groups begin to blur together. The twelve journalists interviewed for this thesis regardless of their role conceptions, their place of employment, or their training strained to be, first and foremost, human beings. Across all camps, compassion and consideration were stressed. Some journalists had experienced trauma of their own and were acutely aware of the weight their words and actions carried. Others had not, but still prioritized the wellbeing and comfort of the survivor throughout the reporting process. Even in dealing with the perpetrators of sexual violence, human connection was something that Journalist $\mathrm{H}$ identified as important to them. Striving for connection and empathy, however, did not mean that the role conceptions and goals of these journalists aligned with the recommendations and priorities laid out by experts on trauma reporting.

There were two points in particular where journalists' understandings and actions aligned with the recommendations of feminist scholars and sexual violence advocates. In determining whether or not to name the survivors featured in their stories, all of the journalists interviewed for this study adhered to what Boyle (2012) described as a 
conspiracy of silence that sexual violence survivors rely on for protection in the United States. Without exception, these journalists described newsroom environments that understood and respected that sexual violence is a personal and traumatic experience that an individual might not want tied to their name forever. It is unclear whether this is due to the fact that nine of the twelve journalists worked at more localized news organizations and therefore had better community mindfulness, or because of a greater understanding of the trauma involved in sexual violence following the \#MeToo movement. Because many of the journalists who agreed to be interviewed were relatively new to the field, they did not have years of prior experience to compare in interrogating their own reporting processes and biases. These journalists were seemingly unlikely to fall back on common rape myths. Among the most prominent identified by Stubbs-Richardson (2018) is the assumption that individuals receive morally just consequences, or the relationship between victim-blaming and the just-world hypothesis. These journalists expressed, in the course of their interviews, that they were empathetic and aware of the difficulties faced by survivors of sexual violence, repeating some version of the phrase, "I want them to know it's okay to tell their story." That support and patience is not typically shown to individuals who are believed to be deserving of whatever pain they are suffering. This was true of journalists across roles and with differing goals.

A majority of the journalists interviewed for this study could best be identified as striving toward monitorial and interpretive roles. Some defining features of those roles, however, are at odds with the recommendations that media and feminist scholars make for improving reporting on sexual violence. One such case is in the use of the word "victim." Blanding (2017) noted that this term can be problematic for some survivors of 
sexual violence as it implies weakness or a loss of agency. Though the journalists interviewed for this study justified their use of "victim" based on style guidelines at their news organizations and crime reporting norms, it is notable that all but one defaulted to using "victim" rather than "survivor" in their copy. Journalist J did, however, raise a particularly interesting point regarding a survivor's individual journey through the healing process and whether or not they are yet comfortable being called a survivor. This is an example of why communication with survivors during the reporting process is essential - when possible. In practice, it is unrealistic to expect that journalists will always be aware of the identities of the people whose stories they are telling and subsequently be able to reach out. Most journalists in this study did agree that, should the survivor express a desire to be referred to in a specific manner, they would do so to the best of their ability - at the very least, in quotes. This aligns with Blanding's (2017) recommendation of determining terminology on a case-by-case basis. Interviewed journalists also diverted from scholars' recommendations concerning the word "alleged." As noted previously, this was primarily due to legal concerns associated with attributing guilt to perpetrators before the justice system has. Hohman (2015) asserted that journalists should avoid using the word "alleged" in their copy and instead attribute statements to the individuals who said them. In the case of the journalists best identified by the monitorial role in particular, "alleged" is seen as a necessity because it allows journalists to refrain from appearing to issue accusations. Although it is not the only means by which to accomplish this, "alleged" fits a norm and tradition in reporting specifically crime reporting - that many journalists do not see as potentially problematic. 
Many of the journalists who best fit the monitorial role, in fact, hastened to contextualize sexual violence reporting within the broader umbrella of crime reporting. When giving an answer, these journalists were quick to add the phrase "as with all crime reporting." These responses were consistent with the 2015 Berkeley Media study that found that more than half of stories about sexual violence focus on criminal justice milestones such as arrest and trial. While sexual violence reporting does technically fall into this category, it is this classification that limits our concept of what that story entails. This falls at the heart of Easteal's (2014) concerns about violence against women being treated as isolated incidents rather than being viewed within the dynamics of social male dominance. It could also, in the case of briefs and other crime reporting, fall within Stubbs-Richardson's (2018) identified pattern of sexual violence being treated as subnews. With this mindset, sexual violence reporting consists of the incident and any legal action that follows but would not go on to include stories relevant to the second and third acts of trauma reporting. These stories might not fit into a news organization's typical perception of sexual violence stories - especially since, as the journalists interviewed for this study have made quite clear, these stories are often seen as a branch or subset of crime reporting. They more likely would be included as features or longform articles - a way of covering sexual violence that several journalists noted would have been unthinkable a decade ago. Armstrong and Mahone (2017) saw willingness to participate in action against sexual violence higher where it is treated as a prominent community concern, and that would require more stories that look at sexual violence beyond a singular incident. Blanding (2017) noted the importance of considering the landscape of sexual violence, as well as returning to speak with survivors a year or more after the 
initial incident. Journalists whose responses aligned best with the monitorial role or who are primarily concerned with the criminal justice aspect of sexual violence reporting may miss this part of the story.

This is not to say that these journalists are deliberately neglecting parts of survivors' stories. Rather, a large part of this disconnect, particularly between monitorial journalists and those more aligned with the radical and humanistic roles, may be attributed to a lack of training specific to reporting on trauma, as well as a lack of access to the very survivors who are their stories' central characters. Boyle (2012) stressed the need for training reporters and editors in order to help them recognize the myths, stereotypes, and unconcious biases present in their reporting. None of the journalists in this sample had formal training related to covering traumatic events, whether during their education or once they were stationed in newsrooms. Those who had dealt closely with resources like Femifesto and rape crisis centers responded in ways that aligned best with the radical and humanistic roles, perhaps because of a greater understanding of the longlasting effects of trauma and greater perceived importance of the later parts of these stories. The goal of the monitorial role - holding individuals and power systems accountable - is by no means misdirected or ill-intentioned. It simply does not extend beyond a certain point in the survivor's story, meaning that the role most normalized among journalists is one that tells an incomplete narrative.

In critiquing this role, we should not undervalue it. Holding those who commit acts of sexual violence accountable is an essential part of combatting a culture that enables and (in some cases) encourages these crimes of control and domination. In turn, the humanistic role would not, by itself, be sufficient, as it does not offer any guidance or 
pressure in the pursuit of justice, whether personal, restorative or criminal. What journalists should - must - find in covering sexual violence is a balance of the four roles laid out in this thesis that holds perpetrators accountable, uplifts and empowers survivors, investigates claims without unintentionally discrediting them, and challenges social norms surrounding sexual violence and intimate partner relations. As the line between the public and a particularly private and personal event, it is essential that we understand what our role is and what it should be. The journalists interviewed for this thesis did not have a single answer to this problem, nor can one study hope to resolve all of the issues embedded in the very culture of reporting on sexual violence. As culture evolves and adapts under the reckoning of the \#MeToo movement, journalism must do the same, and conversations must continue without the assumption that the problem is ever succinctly solved.

\section{Limitations}

When this thesis was initially proposed, it was intended that it would focus on the personal and cultural changes that journalists recognized in reporting on sexual violence in light of the \#MeToo movement. That movement, its online impact and dynamics, and the alteration of reporting culture were at the core of this research. However, in interviewing the twelve journalists in this study and analyzing the transcripts of these interviews, it became clear that the long-term effects of this movement are not easily identifiable or distinguishable from the slow progression of reporting culture that has been taking place for decades - at least not yet. Given the recency of the Weinstein allegations, as well as continuing developments in cases against high-profile individuals 
like Jeffrey Epstein and Donald Trump, calling the \#MeToo movement complete seems premature. This thesis, then, is a checkpoint rather than a definitive analysis of the impact of an ongoing movement. It should be noted that the some of the journalists interviewed for this study may have recognized fewer direct implications of the \#MeToo movement and post-Weinstein period because of the short amount of time they have spent in the field. If a similar study were conducted and brought participation from journalists with more experience, these results might have been different.

This study is limited by its nature as investigative of sexual violence coverage. As noted previously, some who declined to be interviewed said that they did not feel qualified to participate in the study based on the degree to which they had covered sexual violence. Some journalists feel that unless they are experts on the subject of sexual violence, they do not have a place in discussing it at all (outside of reporting on it). Due to the personal nature of trauma and discussing traumatic events, it is also difficult or inappropriate to cross certain boundaries with the journalists who did agree to be interviewed, meaning that some statements regarding personal trauma must exist as is, without further context. While that does not severely hinder the goal of this research, it is a limitation in discussion.

In discussing terminology in sexual violence reporting, the choice between using "victim" and "survivor" often misses an important point - not every individual who has experienced sexual violence is a survivor. This is a nuance that was not discussed with interviewees because it approaches another discussion within domestic violence and would have extended beyond the confines of this paper. However, it is important to note 
that the use of the term "survivor" throughout this paper is not intended to omit or downplay the experiences of victims of sexual violence who did not survive.

\section{Directions for Future Research}

In the months during which this study was conducted (early 2020), Harvey Weinstein was tried and convicted on two counts in State Supreme Court in Manhattan. Justice James A. Burke sentenced Weinstein to 23 years, saying that although the trial resulted in a first conviction, it was not Weinstein's first offense (Ransom, 2020). Because the exposure of Weinstein's crimes kickstarted the public fervor of the \#MeToo movement, it is reasonable to assume that his conviction will also affect how the world views reporting on sexual violence. His case is tangible proof that good reporting can lead to justice. Future research should look at the long-term effects of the \#MeToo movement and the post-Weinstein period on sexual violence reporting. This movement has also seen an increase in accusations made outside of the criminal justice system (primarily on social media), and future research should explore the challenges of verification and empathetic reporting processes within this growing sector.

As of the completion of this study, less than three years have passed since the initial New York Times article was published. Though a lot can happen in three years, Weinstein's conviction represents the potential of a movement rather than the culmination of it. It will be important in the coming years to continue discussing how journalists cover sexual violence, why they cover it the way that they do, and how we can continue to reform our practices to best support survivors and seek truth. Future research might consider pooling more journalists together in focus groups so as to create more 
inter-organizational and inter-journalist discussion of sexual violence reporting norms while doing this analysis. In order to address the concerns raised by Journalists D and E, any future research should also explicitly explore the effects of the \#MeToo movement on reporting in smaller, conservative towns in the United States. Given that a nationwide mainstream outlets are generally perceived as liberal, and this assumption falls to the general "media," these news organizations can be overlooked in research, rather than considered for the valuable insight they may provide.

Another aspect that is important to consider moving forward is the theoretical implications of the \#MeToo movement and post-Weinstein period. Feminist scholarship has, up until this point, considered news reporting as a contained entity in dealing with sexual violence. Social media has, however, begun to change the dynamics of a survivor's ability to take control of their own narrative and journalists' ability to reach out to and cover survivors that would have previously been hidden from view. In the case of Chris D'Elia, for example, the women and girls accusing him of misconduct did not turn to news outlets, but their stories were publicly available and amplified by journalists. As journalists have the opportunity to become more than passive receivers of reports of sexual violence, theorists need to reconsider the responsibilities that accompany that role, particularly in relation to journalism and the treatment of sexual violence as isolated incidents. Under the \#MeToo movement and social media, there is increased understanding of the interconnectedness of sexual violence, but also increasing disagreement on precisely what that means - within a community versus within society. Feminist scholarship needs to hone in on the specific failures and insufficiencies of modern journalism. 


\section{References}

Amnesty International UK (2005, November 21). UK: New poll finds a third of people believe women who flirt partially responsible for being raped. Amnesty International. https://www.amnesty.org.uk/press-releases/uk-new-poll-finds-thirdpeople-believe-women-who-flirt-partially-responsible-being

Anastasio, P. A., \& Costa, D. M. (2004). Twice hurt: How newspaper coverage may reduce empathy and engender blame for female victims of crime. Sex Roles, 51(9-10), 535-542. doi:10.1007/s11199-004-5463-7

Armstrong, C. L. \& Mahone, J. (2017). “It's On Us.” The Role of Social Media and Rape Culture in Individual Willingness to Mobilize Against Sexual Assault. Mass Communications and Society, 20, 90-115. doi:10.1080/15205436.2016.1185127

Bennett, J. (November 5, 2017). The 'Click' Moment: How the Weinstein Scandal Unleashed a Tsunami. The New York Times. https://www.nytimes.com/2017/11/ 05/us/sexual-harrasment-weinstein-trump.html

Blanding, M. (2017, Winter). Covering Sexual Assault. Neiman Reports. https://niemanreports.org/issues/winter-2017/

Boyle, H. (2012). "Rape and the Media: Victim's Rights to Anonymity and Effects of Technology on the Standard of Rape Coverage", European Journal of Law and Technology, 3(3). http://ejlt.org/article/view/172

Brockes, E. (2019, September 25). Chanel Miller on why she refuses to be reduced to the 'Brock Turner sexual assault victim'. The Guardian. https://www.theguardian.com/us-news/2019/sep/25/stanford-sexual-assaultvictim-chanel-miller-interview

Burt, M. R. (1980). Cultural myths and supports for rape. Journal of Personality and Social Psychology, 38(2), 217. doi:10.1037/0022-3514.38.2.217

Carlyle, K. E., Slater, M. D., \& Chakroff, J. L. (2008). Newspaper coverage of intimate partner violence: Skewing representations of risk. Journal of Communication, 58(1), 168-186. doi:10.1111/j.1460-2466.2007.00379.x

Clarke-Vivier, S. \& Stearns, C. (2019). MeToo and the problematic valor of truth, Journal of Curriculum Theorizing, 34(3), 55-75.

Champlin, S. (2017). Everyday life information seeking: Sex-based associations with where men and women receive information about sexual violence. Journal of Communication in Healthcare, 10(4), 285-295.

doi:10.1080/17538068.2017.1385569 
Chappell, B. (2014, September 29). California Enacts 'Yes Means Yes' Law, Defining Sexual Consent. NPR. https://www.npr.org/sections/thetwo-way/2014/09/29/ 352482932/california-enacts-yes-means-yes-law-defining-sexual-consent

Chicago Tribune staff writer (2020, March 11). \#MeToo: A timeline of events. Chicago Tribune. https://www.chicagotribune.com/lifestyles/ct-me-too-timeline20171208-htmlstory.html

Coleman, R. (2018). Why be a journalist? US students' motivations and role conceptions in the new age of journalism. Journalism, 19(6), 800-819. doi: $10.1177 / 1464884916683554$

Darmon, K. (2014) "Framing SlutWalk London: how does the privilege of feminist activism in social media travel into the mass media?" Feminist Media Studies, 14(4). 700-704. doi: 10.1080/14680777.2014.935208

Dorer, Johanna, and Brigitte Hipfl (2013). "Current Perspectives and Future Challenges in Feminism and Media Studies." International Journal of Media \& Cultural Politics, 9(3), 305-313. doi:10.1386/macp.9.3.305_3

Easteal, P. (2014). Enduring themes and silences in media portrayals of violence against women. Women's Studies International Forum. doi:10.1016/j.wsif.2014.10.015

Femifesto. (2015). Use the Right Words: Media Reporting on Sexual Violence in Canada. Toronto. http://www.femifesto.ca/wp-content/uploads/2015/12/UseTheRight Words-Single-Dec3.pdf

Fontana, A. \& Frey, J. (1994). Interviewing: The art of science. Sage Publications, 2-17.

Fountain, A. (2008). It's All in the Words: Determining the Relationship Between Newspaper Portrayal of Rape Victims and Reader Responses. The Undergraduate Review, 4(10), 33-38. https://vc.bridgew.edu/undergrad_rev/vol4/iss1/10

Franiuk, R., Seefelt, J. L., Cepress, S. L., \& Vandello, J. A. (2008). Prevalence and effects of rape myths in print journalism: The Kobe Bryant case. Violence Against Women, 14(3), 297-309. doi:10.1177/1077801207313971

Glaser, B. \& Strauss, A. (1967). The discovery of grounded theory: Strategies for qualitative research. News Brunswick: Aldine Transaction.

Harrington, C. (2018). Feminist Killjoys and Women Scorned: An Analysis of News and Commentary on the Sexual Violence Allegations Against Julian Assange. Feminist Criminology, 13(1), 87-111. doi:10.1177/1557085116646194

Hewitt, H. (2017, November 28). The media can't put the brakes on its sexual assault coverage. The Washington Post. https://www.washingtonpost.com/opinions/themedia-must-keep-covering-in-depth-every-sexual-assault-scandal 
Hinnant, A., Jenkins, J., \& Subramanian, R. (2016). Health journalist role conceptions, Journalism Practice, 10(6), 763-781, doi:10.1080/17512786.2015.1053509

Hohman, M. (2015). The balancing act of sex crimes reporting: A survey of journalists' responses to new standards for sexual assault coverage (Unpublished master's thesis). University of Missouri, Columbia, MO.

Kantor, J. \& Twohey, M. (2017, October 5). Harvey Weinstein Paid Off Sexual Harassment Accusers for Decades. The New York Times. https://www.nytimes.com/2017/10/05/us/ harvey-weinstein-harassmentallegations.html

Kroll, J. (2015). Rolling Stone's problems are also journalism's problems. Editor \& Publisher. https://www.editorandpublisher.com/columns/shoptalk-rolling-stone-sproblems-are-also-journalism-s-problems/

Lecheler, S. \& Hinrichsen, M. (2010). Role conceptions of Brussels correspondents from the new member states. Javnost - The Public, 17(1), 73-86.

Li, J. (2017). “I Believe What I See”: College Students' Use of Media, Issue Engagement, and Perceived Responsibility Regarding Campus Sexual Assault. Journal of Health Communication, 22(9), 772-782. doi:10.1080/10810730.2017.1355419

Maxwell, Z. (2014, March 27). Rape Culture is Real. TIME. http://time.com/40110/rapeculture-is-real/

McDonald, P. \& Charlesworth, S. (2012). Framing sexual harassment through media representations. Women's Studies International Forum. doi:10.1016/j.wsif.2012.11.003

Mellado, C. \& van Dalen, A. (2014). Between rhetoric and practice: Explaining the gap between role conception and performance in journalism, Journalism Studies, 15(6), 859-878, doi: 10.1080/1461670X.2013.838046

Millner, D. (2018, October 25). The movement \& the future. Essence. https://www.essence.com/magazine/tarana-burke-profile-november-2018/

New York Times staff writer (2020, February 24). Full Coverage: Harvey Weinstein Is Found Guilty of Rape. The New York Times. https://www.nytimes.com/2020/ 02/24/nyregion/harvey-weinstein-verdict.html

Ochberg, F. (1999). Three Acts of Trauma News, Sacred Bearings. Retrieved February 20, 2020, from http://www.giftfromwithin.org/pdf/threeact.pdf

O'Hara, S. (2012). Monsters, playboys, virgins and whores: Rape myths in the news media's coverage of sexual violence. Language and Literature, 21(3), 247-259. doi:10.1177/0963947012444217 
Ransom, J. (2020, March 11). Harvey Weinstein's Stunning Downfall: 23 Years in Prison. The New York Times. https://www.nytimes.com/2020/03/11/nyregion/ harvey-weinstein-sentencing.html

Shahryar, J. (2013, March 27). The media can help stop rape. Women's Media Center. http://www.womensmediacenter.com/women-under-siege/how-media-can-helpstop-rape

Siefkes-Andrew, A. J. \& Alexopoulos, C. (2018). Framing blame in sexual assault: An analysis of attribution in news stories about sexual assault on college campuses. Violence Against Women. doi:10.1177/1077801218801111

Stephens, B. (2018, February 20). Free Speech and the Necessity of Discomfort. The New York Times. https://www.nytimes.com/2018/02/22/opinion/free-speechdiscomfort.html

Stubbs-Richardson, M. (2018). Tweeting rape culture: Examining portrayals of victim blaming in discussions of sexual assault cases on Twitter. Feminism \& Psychology, 28(1), 90-108. doi:10.1177/0959353517715874

Tandoc, E. \& Peters, J. (2015). One journalist, two roles: What happens when journalists also work as media coordinators? Journalism, 16(3), 324-340, doi: $10.1177 / 1464884913520199$

Vos, T. (2005). Journalistic role conceptions: A bridge between the reporter and the press. Presented by at the meeting of ICA-Journalism Studies Division, New Jersey.

Zelizer, B. (1993). Journalists as interpretive communities, Critical Studies in Mass Communication, 10, 219-237. 


\section{APPENDIX A}

Recruitment message

Dear

Hello. My name is Beck Jaeckels and I am a graduate journalism student at the University of Missouri. I am reaching out to you in the hopes of conducting an interview related to your work reporting on sexual violence.

This interview would be a part of a larger research study seeking to understand the reporting, editing, and decision-making processes used by reporters when discussing incidents of sexual violence. The purpose of this study is to understand how journalists chose to discuss individuals issuing accusations, perpetrators, and misconduct and investigations and whether the unique conditions of the \#MeToo movement and postWeinstein period affected this thought and decision-making process.

I would greatly appreciate your involvement in this process, as well as any recommendations for peers who you think could shed light on this subject.

If you are interested, please do not hesitate to reach out to me at 414-339-7070 or beckie.jaeckels@mail.missouri.edu. Thank you!

Sincerely,

Beck Jaeckels

becked-out.weebly.com | (414) 339-7070

Teaching Assistant | Columbia Missourian 


\section{APPENDIX B}

Interview guide

This interview is a part of a larger research study seeking to understand the reporting, editing, and decision-making processes used by reporters when discussing incidents of sexual violence. The purpose of this study is to understand how journalists chose to discuss individuals issuing accusations, perpetrators, and misconduct and investigations and whether the unique conditions of the \#MeToo movement and post-Weinstein period affected this thought and decision-making process.

Participation in this study is voluntary, and your identity will be kept confidential. Should you decide at any point during the interview that the subject matter is too distressing, the interview will end. This interview will be audio recorded.

Any questions or concerns after the interview should be directed to Beck Jaeckels at 414339-7070 or beckie.jaeckels@mail.missouri.edu. A hard or digital copy of this information will be provided to you.

Are there any questions I can answer before we begin?

- How did you begin reporting on sexual violence?

- What challenges did you think you were going to face with these stories? Were these the challenges you ended up facing?

- What conversations did you have with editors or peers about writing these articles?

- What deliberate decisions did you make with language in your coverage? (accuse, alleged, claim, victim, survivor, etc.)

- How did you approach the issue of trauma in your reporting?

- What effect has the \#MeToo era had on your reporting?

- How do you balance the norms of verification and objectivity with the goal of believing and supporting survivors?

- What do you think is the ultimate goal of reporting on sexual violence? 